\title{
BOBMEX: The Bay of Bengal Monsoon Experiment
}

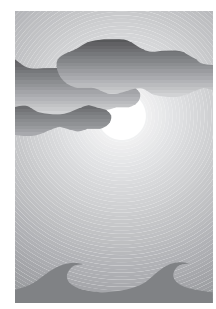

\author{
G. S. Bhat, ${ }^{*}$ S. Gadgil, ${ }^{*}$ P. V. Hareesh Kumar, ${ }^{+}$S. R. Kalsi," ${ }^{+}$P. Madhusoodanan, ${ }^{+}$ \\ V. S. N. Murty, ${ }^{@}$ C. V. K. Prasada Rao, ${ }^{+}$V. Ramesh Babu, ${ }^{@}$ L. V. G. Rao, ${ }^{@}$ \\ R. R. Rao, ${ }^{+}$M. Ravichandran, ${ }^{\&}$ K. G. Reddy, ${ }^{* *}$ P. Sanjeeva Rao, ${ }^{++}$ \\ D. Sengupta, ${ }^{*}$ D. R. Sikka, ${ }^{\# \#}$ J. Swain, ${ }^{+}$and P. N. Vinayachandran*
}

\begin{abstract}
The first observational experiment under the Indian Climate Research Programme, called the Bay of Bengal Monsoon Experiment (BOBMEX), was carried out during July-August 1999. BOBMEX was aimed at measurements of important variables of the atmosphere, ocean, and their interface to gain deeper insight into some of the processes that govern the variability of organized convection over the bay. Simultaneous time series observations were carried out in the northern and southern Bay of Bengal from ships and moored buoys. About 80 scientists from 15 different institutions in India collaborated during BOBMEX to make observations in most-hostile conditions of the raging monsoon. In this paper, the objectives and the design of BOBMEX are described and some initial results presented.

During the BOBMEX field phase there were several active spells of convection over the bay, separated by weak spells. Observation with high-resolution radiosondes, launched for the first time over the northern bay, showed that the magnitudes of the convective available potential energy (CAPE) and the convective inhibition energy were comparable to those for the atmosphere over the west Pacific warm pool. CAPE decreased by $2-3 \mathrm{~kJ} \mathrm{~kg}^{-1}$ following convection, and recovered in a time period of 1-2 days. The surface wind speed was generally higher than $8 \mathrm{~m} \mathrm{~s}^{-1}$.

The thermohaline structure as well as its time evolution during the BOBMEX field phase were found to be different in the northern bay than in the southern bay. Over both the regions, the SST decreased during rain events and increased in cloud-free conditions. Over the season as a whole, the upper-layer salinity decreased for the north bay and increased for the south bay. The variation in SST during 1999 was found to be of smaller amplitude than in 1998. Further analysis of the surface fluxes and currents is expected to give insight into the nature of coupling.
\end{abstract}

\section{Introduction}

The monsoon governs the very pulse of life on the Indian subcontinent. Understanding and predicting the

\footnotetext{
*Indian Institute of Science, Bangalore, India.

+Naval Physical and Oceanographic Laboratory, Kochi, India.

"India Meteorological Department, New Delhi, India.

${ }^{\circledR}$ National Institute of Oceanography, Goa, India.

\&National Institute of Ocean Technology, Chennai, India.

**Department of Meteorology and Oceanography, Andhra University, Visakhapatnam, India.

${ }^{++}$Department of Science and Technology, New Delhi, India.

\#\#Mausam Vihar, New Delhi, India.

Corresponding author address: Sulochana Gadgil, Centre for Atmospheric and Oceanic Sciences, Indian Institute of Science, Bangalore 560 012, India.

E-mail: sulo@caos.iisc.ernet.in

In final form 15 March 2001.

(C)2001 American Meteorological Society
}

variability of the Indian monsoon is, therefore, extremely important for the well-being of over one billion people and the diverse fauna and flora inhabiting the region. The major thrust of the Indian Climate Research Programme (ICRP) is on monsoon variability, on timescales ranging from subseasonal to interannual and decadal, and its impact on critical resources (DST 1996). The monsoon is strongly coupled to the warm oceans surrounding the subcontinent. Most of the monsoon rainfall occurs in association with synoptic-scale systems, that is, the monsoon disturbances, which are generated over these waters and move onto the Indian landmass (e.g., Fig. 1a for the monsoon season of 1999). In particular, the Bay of Bengal (hereafter called the bay) is exceptionally fertile, with a very high frequency of genesis of these systems (Rao 1976).

The distribution of the summer monsoon (JunSep) rainfall over the Indian region is linked to the 
(a)

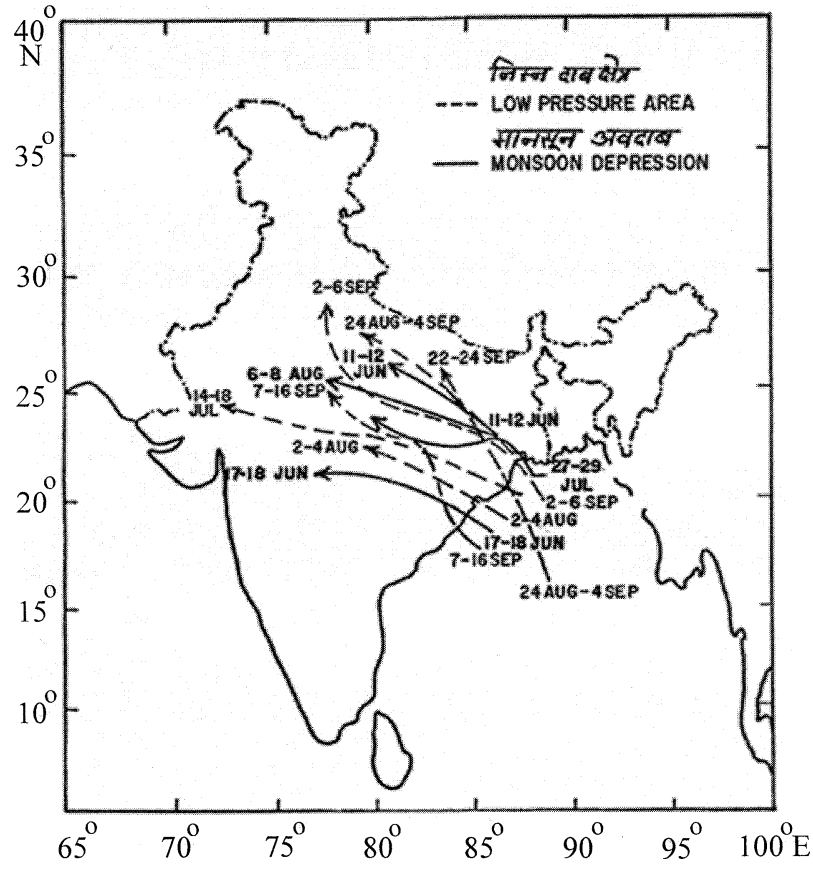

(b)

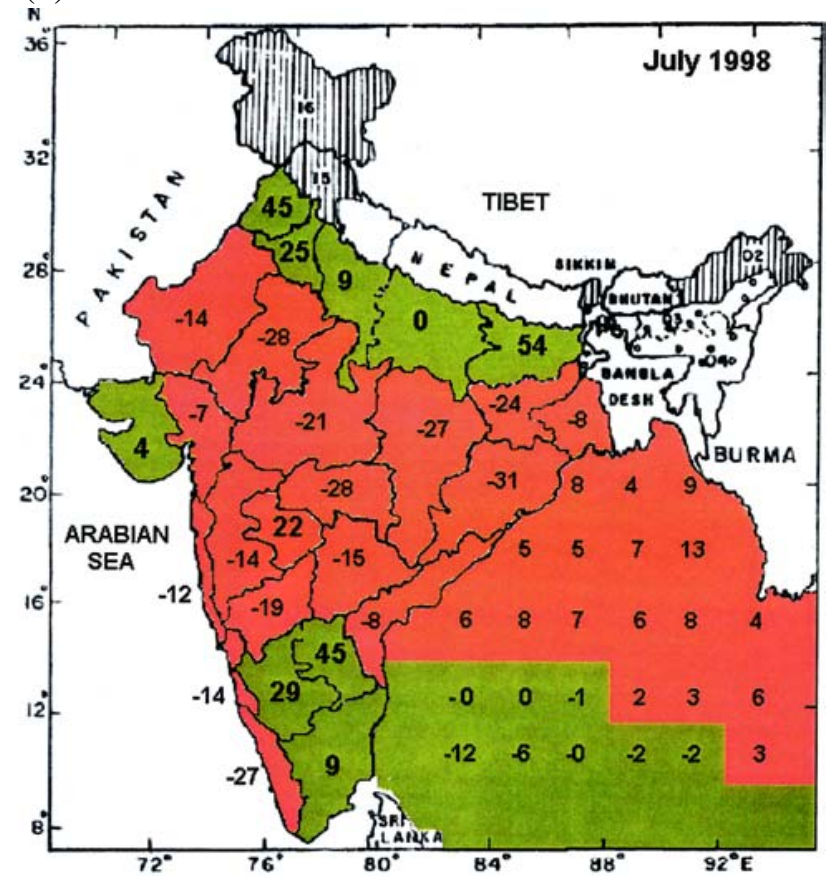

FIG. 1. (a) Tracks of monsoon lows and depressions for the monsoon season of 1999. Monsoon lows and depressions are synoptic-scale systems and identified in a surface pressure chart by one, and two to three closed contours (at 2-mb interval), respectively. (b) OLR anomalies ( $\mathrm{W} \mathrm{m}^{-2}$ ) over the Bay of Bengal and rainfall anomalies (\% of average) over the Indian subcontinent during Jul 1998. Deficit convection (positive OLR anomalies) over the ocean and deficit rainfall (negative rainfall anomalies) over land are marked by red, and greenish yellow refers to normal or above normal convection/precipitation. variation of the convection over the bay (Gadgil 2000). For example, during the summer monsoon of 1998, the convection over the northern bay was anomalously low, with occurrence of relatively few systems, whereas a large number of systems formed over the southern parts of the bay. Thus the anomalies of the outgoing longwave radiation (OLR) were positive over the northern bay and negative over the southern bay (e.g., Fig. 1b for Jul 1998). Most of these systems moved from the southern bay onto and across the southern peninsula. The rainfall anomalies were, therefore, positive over the southern peninsula. Large deficits occurred in the north, particularly over the east coast of India, adjacent to the northern parts of the bay (e.g., Fig. 1b). The 1998 season was not an exceptional one in the distribution of rainfall anomalies over the Indian region; in fact, a similar pattern occurred in 2000.

Summer monsoon rainfall over the Indian region exhibits strong variability on intraseasonal timescales involving a 10-20-day westward propagating mode (Krishnamurti and Bhalme 1976; Krishnamurti and Ardunay 1980) and a 30-50-day northward propagating mode (Sikka and Gadgil 1980; Yasunari 1981). The northward propagations over the bay are clearly seen in Fig. 2, which depicts the variation of microwave sounding unit (MSU) precipitation during the summer of 1986. The major subseasonal variation of the monsoon rainfall can be viewed as alternating active spells and weak spells or breaks (Fig. 3). Active spells are characterized by high frequency of genesis of synoptic-scale systems over the bay, which propagate onto and produce widespread rainfall on the subcontinent; whereas there is a paucity of synoptic systems over central India during a break spell of the monsoon. Revival of the Indian rainfall from monsoon breaks occurs either with the westward propagation of a disturbance generated over the north bay (in association with the 10-20-day mode) or northward propagation of the tropical convergence zone (TCZ) generated over the equatorial Indian Ocean across the bay and Arabian Sea (in association with the 30-50-day Madden-Julian mode). Thus, convection over the bay plays an important role in the variation of synoptic-scale systems as well as in the intraseasonal variation in which these systems are embedded. Interannual variation of the monsoon is strongly linked to the intraseasonal variation, with poor monsoon seasons characterized by long breaks (e.g., Fig. 3). Clearly, for understanding variations of the monsoon over the Indian subcontinent on intraseasonal as well as interannual timescales, it is 


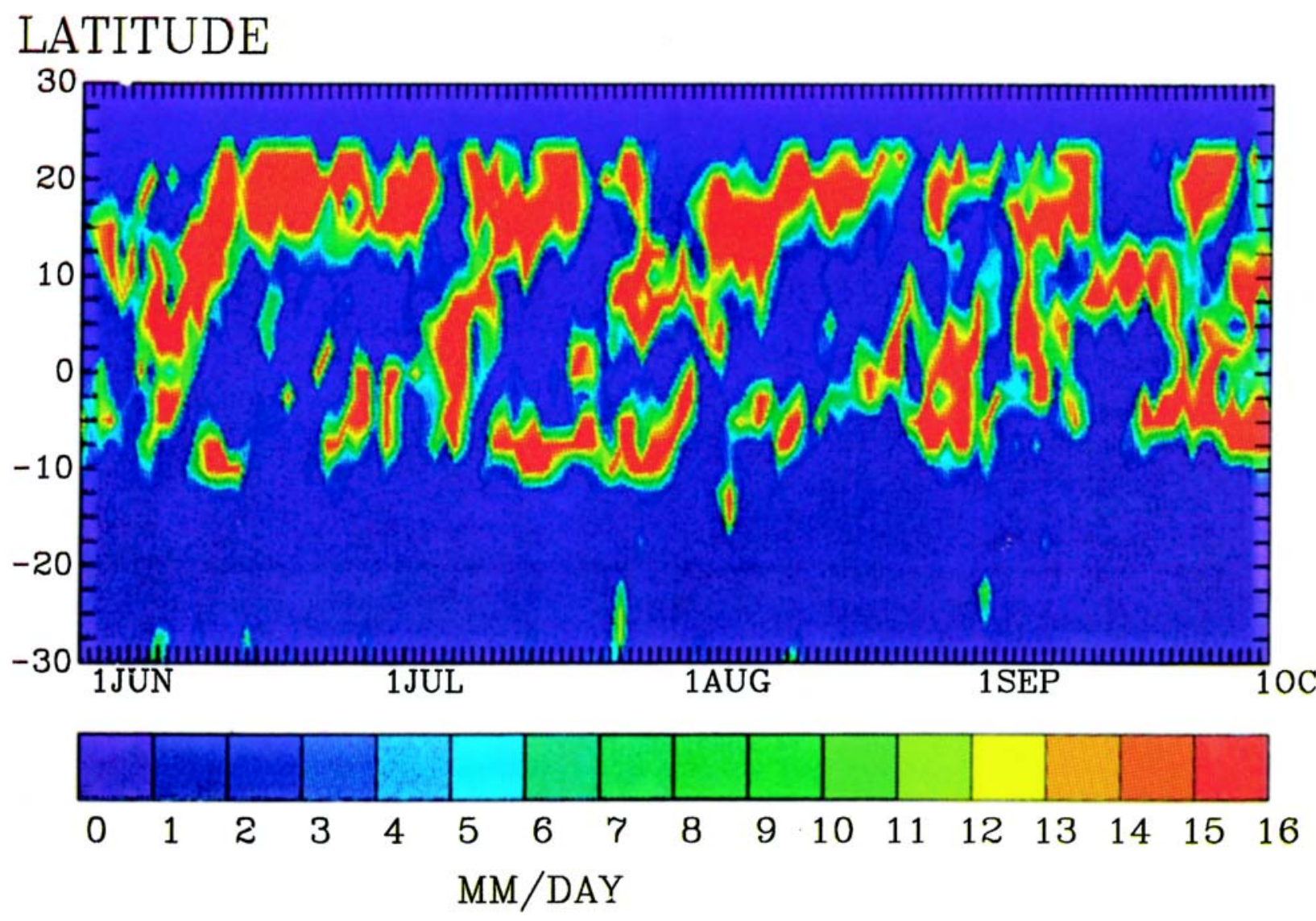

FIG. 2. Variation of rainfall measured by MSU over the $90^{\circ}-92.5^{\circ} \mathrm{E}$ longitudinal belt during the summer monsoon of 1986 . (Courtesy J. Srinivasan.)

important to understand processes that determine the variability of organized convection over the bay.

The intraseasonal variation over the bay is clearly brought out in the observed SST and wind speed from a moored buoy and Indian National Satellite System (INSAT) OLR (outgoing longwave radiation) data during July-August 1998 (Fig. 4). It is seen that the dominant timescale of variation of OLR, wind speed, and SST is intraseasonal, with the maxima-minima separated by about 1 month. During this 2-month period, three spells of low OLR were observed. The amplitude of variation of SST can be about $2{ }^{\circ} \mathrm{C}$ in the north bay (Fig. 4a). The amplitude and timescales of variation in SST appear to be comparable to those in the equatorial west Pacific Ocean (Anderson et al. 1996). The phases with decreasing (increasing) OLR are generally associated with decreasing (increasing) SST, with changes in OLR leading those in SST by a few days. Sengupta and Ravichandran's (2001) study has shown that the net heat flux into the ocean is negative in the active phase of convection and positive in the weak phase of convection in the bay; the observed
SST changes in these phases appear to be largely due to a direct response to the changes in net heat flux.

Earlier studies suggest that atmospheric conditions have a significant impact on the SST of the bay. However, the extent to which variation of SST modulates the convection over the bay is not known. The problem is complex because the SST of the bay is above the convection threshold of $27.5^{\circ} \mathrm{C}$ (Gadgil et al. 1984; Graham and Barnett 1987) throughout the summer. Understanding the nature of the feedbacks between the atmospheric convection and surface conditions of the bay is important for understanding the variability of convection over the bay. A major international program, the Tropical Ocean Global Atmosphere Coupled Ocean-Atmosphere Response Experiment (TOGA COARE), aimed at elucidating the coupling of the west Pacific warm pool to the atmosphere (Webster and Lukas 1992), has given considerable insight into ocean-atmosphere coupling on intraseasonal timescales (Godfrey et al. 1998; Shinoda et al. 1998). However, there are important differences between the thermohaline structure of the bay and the 

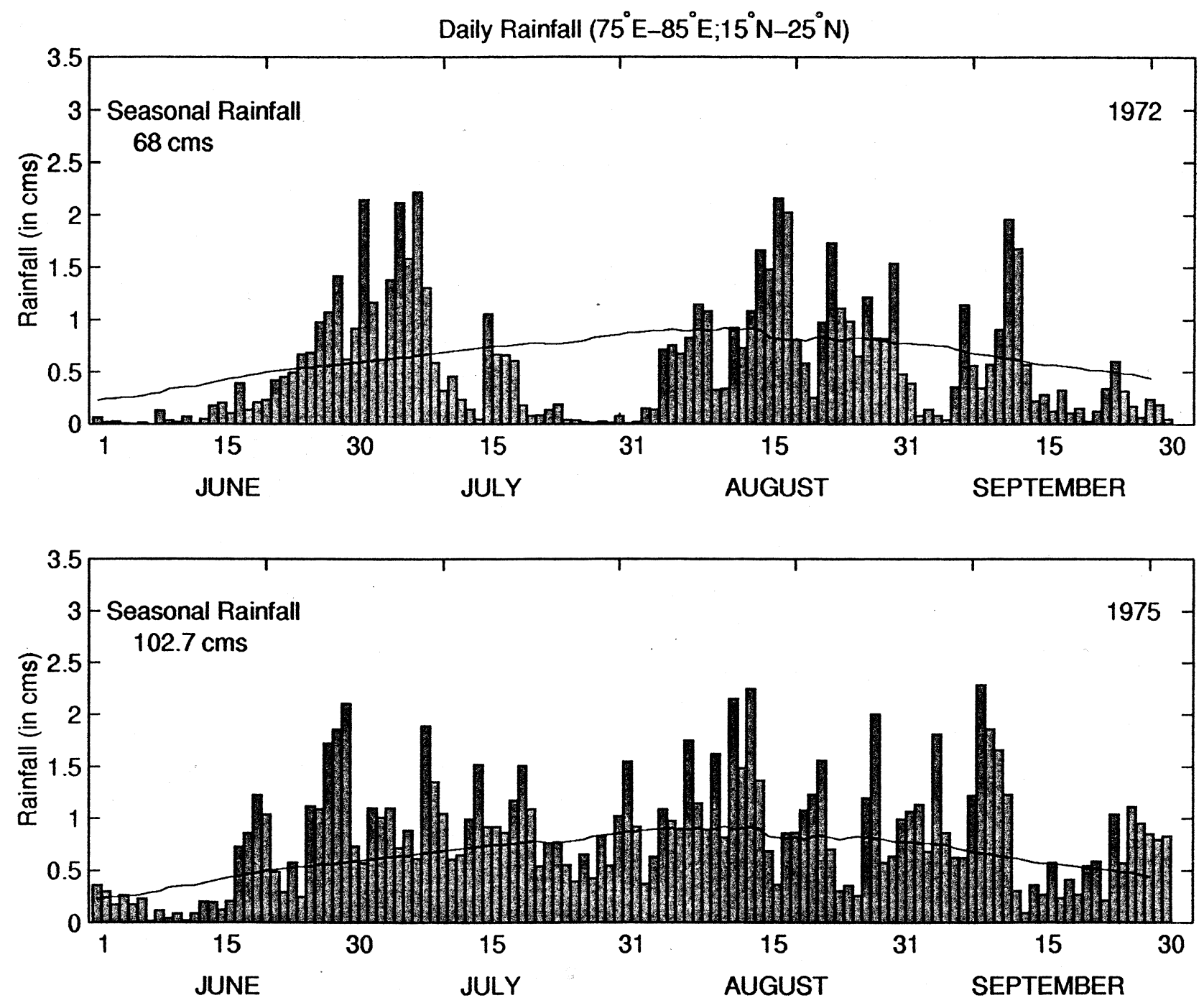

FIG. 3. Daily rainfall over central India during 1972 and 1975, which were deficit and excess monsoon rainfall years, respectively. In 1972, active and weak rain spells were well separated with the break during the last week of Jul and first week of Aug clearly seen, whereas in 1975, although there were days of heavy rainfall (active spell), there were no clear-cut breaks.

west Pacific (Varkey et al. 1996) as well as in the atmospheric forcing over these two regions. During the summer monsoon season, the bay receives a large amount of freshwater from rain. The north bay also receives a comparable amount of freshwater from river runoff (Shetye and Gouveia 1998). As a result, the near-surface layer $(0-30 \mathrm{~m})$ of the north bay has relatively fresh water throughout the summer (Murty et al. 1992, 1996; Sprintall and Tomczak 1992). Over the west Pacific, a near-surface layer of relatively fresh water, with a barrier layer beneath, appears intermittently (Godfrey and Lindstrom 1989; Lukas and Lindstrom 1991). Further, the salinity gradient between the surface layer of the west Pacific and the ocean below is much smaller than that over the bay. There are important differences in the atmospheric forcing over these two regions. Over the west Pacific the winds are light, only occasionally exceeding $4 \mathrm{~m} \mathrm{~s}^{-1}$ (Weller and Anderson 1996), whereas over the bay they are much stronger during the monsoon, often greater than $8 \mathrm{~m} \mathrm{~s}^{-1}$. Also, the amplitude of SST variation on a 30-90-day Madden-Julian oscillation timescale is weak and about $0.15^{\circ} \mathrm{C}$ over the Indian Ocean compared to about $0.25^{\circ} \mathrm{C}$ over the west Pacific (Shinoda et al. 1998). Perhaps the intraseasonal oscillations shorter than the 30-day timescale are more important in the Indian Ocean. This points to the need of a special observational experiment over the bay for understanding the nature of the coupling between the atmosphere and the ocean.

Under the ICRP, a special observational program called the Bay of Bengal Monsoon Experiment 
(BOBMEX) was conducted during July-August 1999. BOBMEX was aimed at collecting critical data on the subseasonal variation of important variables of the atmosphere, ocean, and their interface to gain deeper insight into some of the processes that govern the variability of organized convection over the bay and its impact. About 80 scientists from 15 different institutions in India collaborated during BOBMEX to make observations in the hostile conditions of the monsoon. This paper is written with a view to introducing BOBMEX to the international scientific community and presenting a few initial results. Several questions raised by the preliminary analysis of BOBMEX data are being addressed at present with detailed investigations. We expect BOBMEX observations to complement the observations from the pilot study for the Joint Air-Sea Monsoon Interaction Experiment carried out in the southern Bay of Bengal during May-June and September 1999 (Webster et al. 2000, manuscript submitted to Bull. Amer. Meteor. Soc.).

We briefly discuss the background in the next section, and the scientific objectives and the design of the experiment in section 3. In section 4, the sensors, instruments, and the observations during the intercomparison experiments are briefly described. We consider the general features of the variation of convection and the surface variables over the bay during BOBMEX in section 5. Some results from the observations of the atmosphere and ocean are presented in sections 6 and 7, respectively, and concluding remarks in section 8 .

\section{Background}

\section{a. Earlier observational experiments}

Two major international observational experiments were conducted over the bay in the 1970s, namely, MONSOON-77 and MONEX-79. MONSOON-77 involved four Soviet Union (USSR) ships forming a polygon over the bay centered at $17^{\circ} \mathrm{N}, 89^{\circ} \mathrm{E}$ during 11-19 August 1977. A trough formed in the north bay on 16 August and developed into a depression on 19 August. During MONEX-79 (Fein and Kuettner 1980), four USSR ships and upper ocean current meter moorings formed a stationary polygon centered at $16.2^{\circ} \mathrm{N}, 89.5^{\circ} \mathrm{E}$ during $11-24$ July 1979 . In addition, data were collected with dropwindsondes from aircrafts. This period happened to be a weak phase of convection over the bay, and hence disturbed condi- (a)
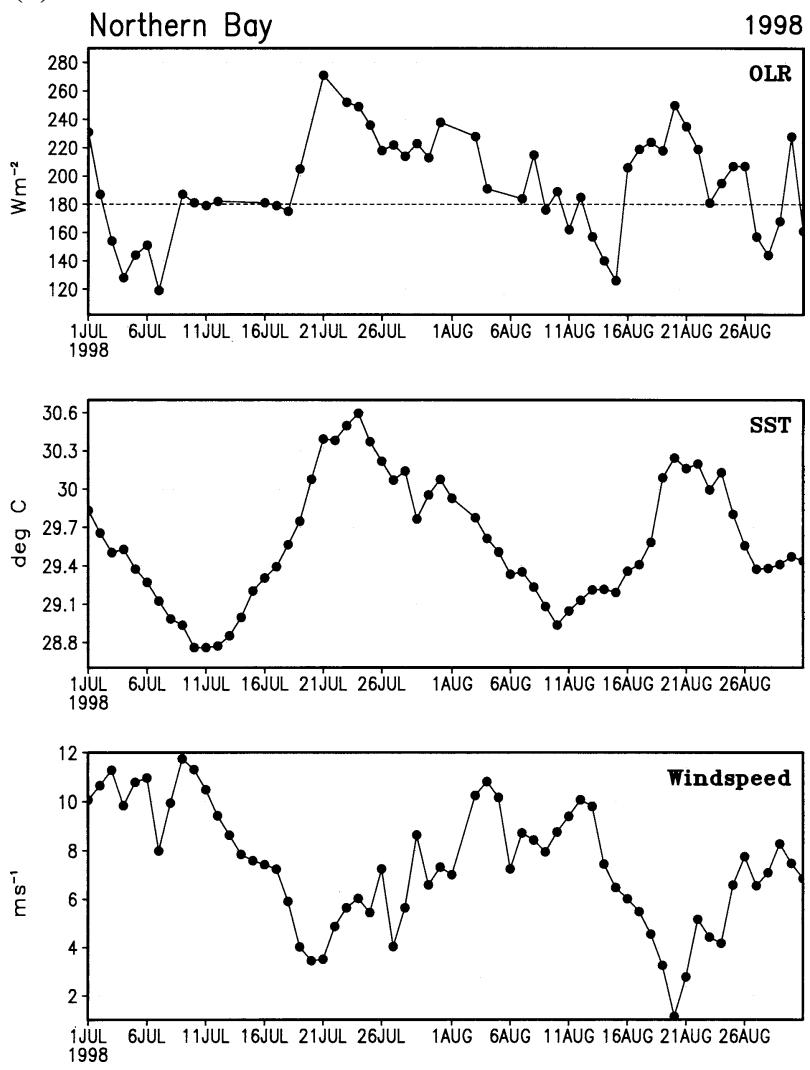

(b)
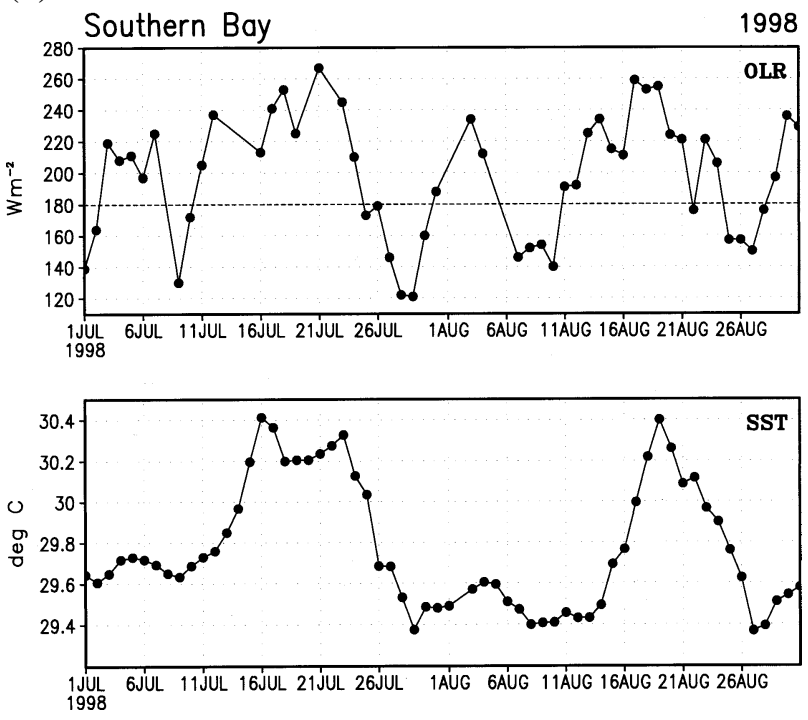

FIG. 4. Variation of INSAT OLR and SST from moored buoys during Jul-Aug 1998 (after Premkumar et al. 2000). (a) North bay $\left(18^{\circ} \mathrm{N}, 88^{\circ} \mathrm{E}\right)$. Wind speed (3-m height) from the buoy is also shown. (b) South bay $\left(13^{\circ} \mathrm{N}, 87^{\circ} \mathrm{E}\right)$.

tions could not be studied. Apart from these two major experiments, observations from a ship were made at $20^{\circ} \mathrm{N}, 89^{\circ} \mathrm{E}$ during $18-31$ August and 9-19 Sep- 
tember 1990, coinciding with the Monsoon Trough Boundary Layer Experiment (MONTBLEX-90) carried out over the northern plains of the Indian subcontinent (Goel and Srivastava 1990).

The differences in the horizontal wind fields, vertical velocity, and large-scale heat and moisture budgets between disturbed and undisturbed conditions in the bay were studied by analysis of these data (e.g., Mohanty and Das 1986). Studies based on the data from these experiments suggest that the genesis of the synoptic-scale systems occurs over regions of the bay with high SST and high heat content in the surface layer (Rao et al. 1987; Sanil Kumar et al. 1994). The impact of the synoptic-scale systems on the ocean beneath was found to be a decrease in SST that can be as large as $2^{\circ}-3^{\circ} \mathrm{C}$ for the most intense systems (Rao 1987; Gopalakrishnan et al. 1993). Observations during MONTBLEX-90 indicated that SST decreased by $0.2^{\circ}-0.3^{\circ} \mathrm{C}$ for weaker systems (Murty et al. 1996; Sarma et al. 1997). The SST increases after the system attenuates or moves away. The timescale for this recovery was about a week for the systems observed during MONEX-79 (Rao 1987; Gopalakrishna et al. 1993).

\section{b. New observations required}

Previous observational experiments (MONEX-79, in particular) have contributed to our knowledge of the large-scale features of the Indian summer monsoon (Krishnamurti 1985). However, detailed observations for studying the vertical structure of the atmosphere, ocean, and their interface during all phases of convection were not available for the bay. Further, all components of the surface fluxes have not been directly measured over the north bay previously. Accurate measurements of surface fluxes over the west Pacific have led to realistic simulations of SST with ocean mixed layer models (Anderson et al. 1996). The summer mean surface salinity in the north bay is very low (Levitus and Boyer 1994) and SSTs are high. It is likely that the high upper ocean stability in this region (Rao et al. 1993) is responsible for the persistent high SST. The upper ocean processes in the presence of strong monsoonal winds and low surface salinity need to be understood. Therefore, it is important to measure heat and freshwater fluxes over the bay with sufficient accuracy, along with upper ocean temperature and salinity profiles. Within the bay, there are marked variations in the freshwater flux between the northern and southern parts. Hence, measurements of fluxes in each of these regions are required.
Variation of convection in the atmosphere depends upon dynamics as well as thermodynamics. There is considerable understanding of the structure and dynamics of the synoptic-scale systems over the bay (e.g., Rao 1976; Sikka 1977). However, there have not been many detailed observations of the vertical structure of the atmosphere over the bay using highresolution radiosondes. Hence, the variation in the stability of the atmosphere and its links with variation in convection are yet to be elucidated. We expect feedbacks between convection and the thermodynamics to play an important role in determining variation of convection (Emanuel 1994, chapter 15). A critical parameter for atmospheric convection is the convective available potential energy (CAPE), a measure of the vertical instability of the atmosphere under moist convection (Moncrief and Miller 1976). CAPE is the work done by the buoyancy force on a parcel lifted through the atmosphere moist adiabatically and is given by (e.g., Williams and Renno 1993)

$$
\mathrm{CAPE}=-\int_{\mathrm{LFC}}^{\mathrm{LNB}}\left(T_{\mathrm{vp}}-T_{\mathrm{ve}}\right) R_{D} d(\ln p)
$$

where $\mathrm{R}_{\mathrm{D}}$ is the gas constant of dry air; $T_{\mathrm{vp}}$ and $T_{v e}$, are, respectively, the virtual temperatures of the parcel and the environment at pressure $p$; and LFC and LNB are levels of free convection and neutral buoyancy, respectively. Deep clouds can develop by the ascent of air from a given level only if its CAPE is greater than zero. When disturbances occur, precipitation, strong winds, and downdrafts decrease the energy of the air near the surface, while deep cloud activity makes the upper troposphere warmer. As a result, the atmosphere becomes less unstable and CAPE is substantially reduced during disturbances (Emanuel 1994, chapter 15). When disturbances attenuate, the air-sea fluxes increase the energy of the surface air, while the temperature of the air aloft decreases because of radiative cooling. These factors destabilize the atmosphere and build up CAPE. The period between successive disturbances is expected to depend upon the time it takes for the CAPE to build up. How the instability builds up, the changes that take place with the growth/arrival of monsoon disturbances, how much instability is consumed, and the manner in which it recovers after the disturbance are the basic issues that are yet be understood for the bay. It is also important to understand if there are any critical values of the height of the atmospheric boundary 
layer and air properties (such as moist static energy and equivalent potential temperature) vis-à-vis the thermal stratification of the atmosphere above, for the onset of convection.

Normally air is not saturated to start with and a finite vertical displacement (a few hundred meters to a few kilometers) is needed for the rising air parcel to become saturated and reach the level of free convection. Some energy is required for this process, and is called convection inhibition energy [CINE, after Williams and Renno (1993)]. CINE is calculated from the integral (Williams and Renno 1993)

$$
\mathrm{CINE}=\int_{p_{i}}^{\mathrm{LFC}}\left(T_{\mathrm{vp}}-T_{\mathrm{ve}}\right) R_{D} d(\ln p)
$$

where $p_{i}$ is the parcel's starting pressure level. It is expected that a larger value of CINE means an increased barrier to convection. If CINE is large, deep clouds will not develop even if CAPE is positive. While low values of CINE imply a favorable condition for convection, the critical value of CINE above which convection cannot occur has not been established. For the estimation of CAPE and CINE, temperature and humidity data with high vertical resolution are required. Such data were not available for the atmosphere over the north bay, prior to BOBMEX.

\section{Scientific objectives and design of the experiment}

A study of the impact of convection on the ocean, the recovery/changes after the convection attenuates and/or moves away, and the characteristics during calm phases when convection is absent for several days was envisaged. The emphasis of BOBMEX was on collecting high quality data during different phases of convection over the bay, which can give insight into the nature of coupling between the convective systems and the bay.

In brief, the scientific objectives of BOBMEX were to document and understand, during different phases of convection, the variations of (i) the vertical stability of the atmosphere and the structure of the atmospheric boundary layer, (ii) fluxes at the surfaces of the ocean, and (iii) the thermohaline structure and the upper ocean currents. (a)

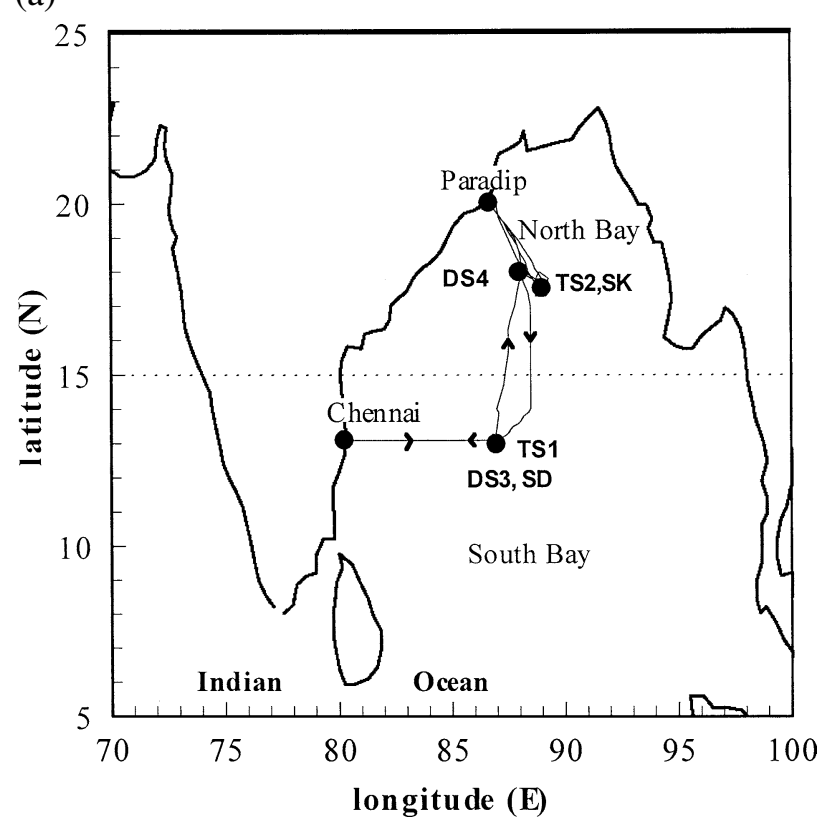

(b)

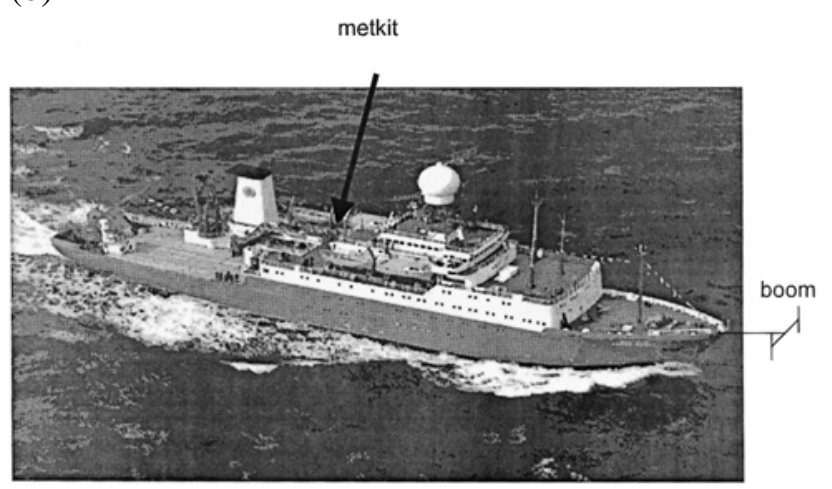

FIG. 5. (a) Cruise tracks, time series observation stations (TS1 and TS2), and buoy locations (DS3 and DS4) in the Bay of Bengal during BOBMEX. Period: 16 Jul-30 Aug 1999. SK, RV Sagar Kanya; SD, INS Sagardhwani. Observation positions: TS $1,13^{\circ} \mathrm{N}$, $87^{\circ} \mathrm{E}$; TS2, $17.5^{\circ} \mathrm{N}, 89^{\circ} \mathrm{E}$; DS3, $13^{\circ} \mathrm{N}, 87^{\circ} \mathrm{E}$; and DS4, $18^{\circ} \mathrm{N}$, $88^{\circ}$ E. (b) The RV Sagar Kanya. The boom and manual surface meteorological observation (metkit) positions are indicated.

\section{Experiment design}

In this first major Indian experiment, it was not possible to deploy as large a number of observation platforms as we would have liked. The two deep moored buoys that provided valuable data during the monsoon of 1998 were stolen a few months before the experiment. Since buoy data are a critical component of BOBMEX, new buoys were installed in the northern and southern bay (henceforth referred to as DS4 and DS3, respectively) during the initial phase of BOBMEX (Fig. 5a). In addition, RV Sagar Kanya $(S K)$, a research vessel belonging to the Department of 
Ocean Development, and INS Sagardhwani (SD), of the Naval Physical and Oceanographic Laboratory of the Defence Research and Development Organisation, were deployed. The India Meteorological Department organized special observations from coastal and island stations.

The timescales of intraseasonal variation are of the order of 3-4 weeks for the bay (Fig. 4). The time series from the earlier observational experiments were too short to reveal variations on these supersynoptic scales. Hence, it was decided to aim for time series observations for about 6 weeks. Two locations-one each in the southern and northern bay-were chosen for the time series observations (henceforth referred to as TS1 and TS2, respectively; see Fig. 5a). The choice of these two locations was based on the following consideration. The occurrence of organized convection is high at both the locations. During the northward propagation of the tropical convergence zone the systems tend to move across the bay from south to the north (Sikka and Gadgil 1980). Therefore, it is important to document the gradients in atmospheric variables and SST between these two regions. Also, there are marked differences in the freshwater fluxes at these two locations and hence in the thermohaline structure of the upper layers of the ocean. The differences, if any, in the response of the ocean to convection at these locations could provide further insight into coupling. In fact, the choice of the location of the buoys was based on a similar rationale. The locations of the research ships for time series observations were chosen to be close to the buoys so that reliability of the observations from two independent platforms could also be assessed. The cruise tracks of the two ships and buoy locations are also shown in Fig. 5a. In addition to the observations at stationary positions in the northern and southern bay, observations were made along zonal sections when the ships made port calls (at Paradip and Chennai) and north-south sections at the beginning and the end of the experiment (Fig. 5a).

Measurements of all components of surface fluxes, including radiation; the vertical profiles of atmospheric temperature, humidity, and winds; and ocean temperature, salinity, and current profiles were planned from both the ships.

\section{Sensors, instruments, and intercomparison}

The basic surface meteorological variables measured were wind (speed and direction), temperature (dry bulb, wet bulb, and sea surface), humidity, pressure, radiation, and precipitation. In order to calculate the fluxes by direct methods, wind velocity, temperature, humidity, and ship acceleration and tilt were measured using fast response sensors at $10 \mathrm{~Hz}$. The major meteorological sensors and instruments used on the ships and buoys are listed in Table 1 . The location of the boom and manual (metkit) observation position on the Research Vessel $S K$ are shown in Fig. 5b.

TABLE 1. Major meteorological sensors/instruments operated during BOBMEX.

\begin{tabular}{|c|c|c|c|c|c|c|c|}
\hline Parameter & $\begin{array}{l}\text { Plat- } \\
\text { form }\end{array}$ & Sensor/instrument & Location $^{\mathbf{a}}$ & Make & Accuracy & $\begin{array}{c}\text { Averaging } \\
\text { time }\end{array}$ & $\begin{array}{c}\text { Sampling } \\
\text { interval }\end{array}$ \\
\hline \multirow[t]{3}{*}{ Wind } & $S K$ & $\begin{array}{l}\text { Hand-held cup } \\
\text { anemometer } \\
\text { (metkit), } \\
\text { sonic anemometer, } \\
\text { Gill anemometer }\end{array}$ & $\begin{array}{c}\text { Deck }(\sim 14 \mathrm{~m}) \\
\text { Boom }(\sim 11.5 \mathrm{~m}) \\
\text { Boom }(\sim 11.5 \mathrm{~m})\end{array}$ & $\begin{array}{l}\text { Ogawaseiki, Japan } \\
\text { Metek, Germany } \\
\text { R. M. Young, U.S.A. }\end{array}$ & $\begin{array}{l}0.1 \mathrm{~m} \mathrm{~s}^{-1} \\
0.2 \mathrm{~m} \mathrm{~s}^{-1}\end{array}$ & $\begin{array}{l}1 \mathrm{~min} \\
1 \mathrm{~min}\end{array}$ & $\begin{array}{c}3 \mathrm{~h} \\
\text { Continuous, } 0.1 \mathrm{~Hz} \\
\text { Continuous, } 0.1 \mathrm{~Hz}\end{array}$ \\
\hline & $S D$ & $\begin{array}{l}\text { Hand-held } \\
\text { cup anemometer }\end{array}$ & $\operatorname{Deck}(\sim 10 \mathrm{~m})$ & - & - & $\mathrm{b}$ & $3 \mathrm{~h}$ \\
\hline & DS3 & Cup anemometer & Tower $(3 \mathrm{~m})$ & Lambrecht & $1.5 \% \mathrm{FS}$ & $10 \min ^{\mathrm{c}}$ & $3 \mathrm{~h}$ \\
\hline
\end{tabular}

${ }^{a}$ Numbers inside the parentheses are approximate heights above the sea surface.

${ }^{\text {b}}$ The hand-held instruments were typically exposed for $3 \mathrm{~min}$.

'From samples collected at $1 \mathrm{~Hz}$. 
TABLE 1. (Continued.)

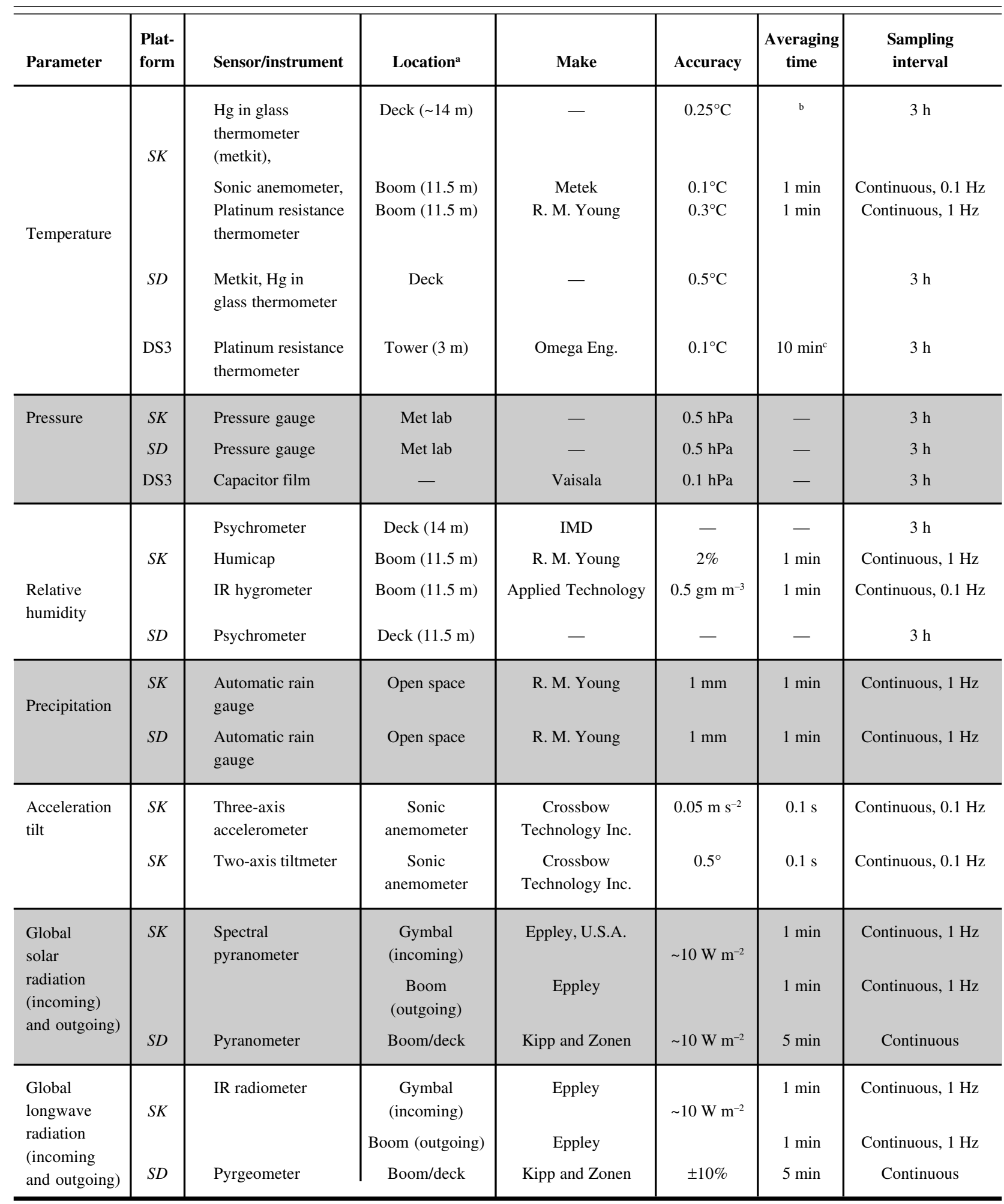

${ }^{a}$ Numbers inside the parentheses are approximate heights above the sea surface.

${ }^{\mathrm{b}}$ The hand-held instruments were typically exposed for $3 \mathrm{~min}$.

${ }^{\mathrm{c}}$ From samples collected at $1 \mathrm{~Hz}$. 
The boom was a 7-m-long horizontal shaft with provisions to fix sensors. Measurement of the vertical profiles of temperature, humidity, and wind were possible only from $S K$. In addition, atmospheric ozone and aerosol concentrations have been measured by the scientists from the Indian Institute of Tropical Meteorology, in Pune. The basic oceanographic variables measured include current, temperature, salinity, wave height and period, chlorophyll, and light transmission. The major oceanographic sensors and instruments used are given in Table 2. Chemical analysis of the water samples for dissolved oxygen, nutrients, dimethylsulfide, and nitrous oxide were carried out. The results of the analysis of atmospheric-oceanic chemistry will be presented separately.

BOBMEX envisaged the use of a large number of state-of-the-art sensors and instruments, some of them used for the first time on an Indian research ship. In order to test the new sensors acquired for BOBMEX and to evolve strategies for coordination among different agencies, data quality control, acquisition, archival, dissemination, and analysis, a pilot experiment

TABLE 2. Major oceanographic instruments used during BOBMEX.

\begin{tabular}{|c|c|c|c|c|c|c|c|}
\hline Parameter & $\begin{array}{l}\text { Plat- } \\
\text { form }\end{array}$ & Sensor/instrument & Make/model & Range & Accuracy & Resolution & $\begin{array}{c}\text { Sampling } \\
\text { Interval }\end{array}$ \\
\hline $\begin{array}{l}\text { Water } \\
\text { column } \\
\text { temperature }\end{array}$ & $\begin{array}{l}S K \\
S D\end{array}$ & $\begin{array}{c}\text { CTD } \\
\text { Mini-CTD }\end{array}$ & $\begin{array}{c}\text { SBE model } 911 \\
\text { plus } \\
\text { SD } 204\end{array}$ & $\begin{array}{l}-5^{\circ} \text { to } 35^{\circ} \mathrm{C} \\
-2^{\circ} \text { to } 40^{\circ} \mathrm{C}\end{array}$ & $\begin{array}{l} \pm 0.01^{\circ} \mathrm{C} \\
\pm 0.01^{\circ} \mathrm{C}\end{array}$ & $\begin{array}{l}0.0002^{\circ} \mathrm{C} \\
0.005^{\circ} \mathrm{C}\end{array}$ & $\begin{array}{l}3 \mathrm{~h} \\
3 \mathrm{~h}\end{array}$ \\
\hline $\begin{array}{l}\text { Water } \\
\text { column } \\
\text { conductivity }\end{array}$ & $\begin{array}{l}S K \\
S D\end{array}$ & $\begin{array}{c}\text { CTD } \\
\text { Mini-CTD }\end{array}$ & $\begin{array}{c}\text { SBE model } 911 \\
\text { plus } \\
\text { SD } 204\end{array}$ & $\begin{array}{l}0-7^{\mathrm{a}} \\
0-7^{\mathrm{a}}\end{array}$ & $\begin{array}{l} \pm 0.0003^{\mathrm{a}} \\
\pm 0.002^{\mathrm{a}}\end{array}$ & $\begin{array}{c}0.00004^{\mathrm{a}} \\
0.001^{\mathrm{a}}\end{array}$ & $\begin{array}{l}3 \mathrm{~h} \\
3 \mathrm{~h}\end{array}$ \\
\hline Pressure & $\begin{array}{l}S K \\
S D\end{array}$ & $\begin{array}{c}\text { CTD } \\
\text { Mini-CTD }\end{array}$ & $\begin{array}{l}- \\
-\end{array}$ & $\begin{array}{l}\text { Up to } 6800-\mathrm{m} \\
\text { depth } \\
\text { Up to } 500-\mathrm{m} \\
\text { depth }\end{array}$ & $\begin{array}{l} \pm 0.015 \%^{\mathrm{b}} \\
\pm 0.02 \% \mathrm{~b}\end{array}$ & $\begin{array}{l}0.001 \%^{\mathrm{b}} \\
0.01 \%{ }^{\mathrm{b}}\end{array}$ & $\begin{array}{l}3 \mathrm{~h} \\
3 \mathrm{~h}\end{array}$ \\
\hline $\begin{array}{l}\text { Horizontal } \\
\text { current }\end{array}$ & $\begin{array}{c}S K \\
S D \\
\text { DS3 }\end{array}$ & $\begin{array}{l}\text { VM-ADCP } \\
\text { VM-ADCP } \\
\text { Acoustic } \\
\text { Doppler }\end{array}$ & $\begin{array}{c}\text { RD Instruments } \\
\text { RD Instruments } \\
\text { UCM60 }\end{array}$ & $\begin{array}{c}250 \mathrm{~m}^{\mathrm{c}} \\
250 \mathrm{~m}^{\mathrm{c}} \\
-\end{array}$ & $\begin{array}{l} \pm 1 \mathrm{~cm} \mathrm{~s}^{-1} \\
\pm 1 \mathrm{~cm} \mathrm{~s}^{-1} \\
1 \mathrm{~cm} \mathrm{~s}^{-1}\end{array}$ & $0.01 \mathrm{~cm} \mathrm{~s}^{-1}, 0.2^{\circ}$ & $\begin{array}{l}10 \mathrm{~min} \\
10 \mathrm{~min} \\
3 \mathrm{~h}\end{array}$ \\
\hline Wave & $\begin{array}{c}S K \\
S D \\
\text { DS3 }\end{array}$ & $\begin{array}{c}\text { SWR }^{\mathrm{d}} \\
\mathrm{SWR} \\
\text { Accelerometer } \\
\text { and compass }\end{array}$ & $\begin{array}{c}- \\
- \\
\text { MRV-6 }\end{array}$ & $\begin{array}{l}- \\
-\end{array}$ & $\begin{array}{c}- \\
- \\
10 \mathrm{~cm}\end{array}$ & & \\
\hline SST & $\begin{array}{l}S K \\
S D \\
\text { DS3 }\end{array}$ & $\begin{array}{c}\text { Bucket } \\
\text { thermometer, } \\
\text { bucket } \\
\text { thermometer, } \\
\text { Platinum resistance } \\
\text { thermometer }\end{array}$ & $\begin{array}{l}\text { T. F. and Co., } \\
\text { Germany } \\
- \\
\text { UCM-60 }\end{array}$ & $\begin{array}{c}-13^{\circ} \text { to } 42.5^{\circ} \mathrm{C} \\
- \\
-5^{\circ} \text { to } 45^{\circ} \mathrm{C}\end{array}$ & $\begin{array}{l}0.25^{\circ} \mathrm{C} \\
0.5^{\circ} \mathrm{C} \\
0.1^{\circ} \mathrm{C}\end{array}$ & $\begin{array}{l}- \\
- \\
-\end{array}$ & $\begin{array}{l}3 \mathrm{~h} \\
3 \mathrm{~h} \\
3 \mathrm{~h}\end{array}$ \\
\hline
\end{tabular}

${ }^{\text {a Siemens }}{ }^{-1}$.

${ }^{b}$ Percent of full scale.

${ }^{\mathrm{c}}$ Maximum profiling range.

${ }^{\mathrm{d}}$ Shipborne wave recorder. 
was carried out during October-November 1998 in the southern bay on board $S K$ (Sikka and Sanjeeva Rao 2000). Preliminary results have been published (e.g., Bhat et al. 2000; Ramesh Babu et al. 2000) and further analysis of these data is being carried out.

Considerable efforts have been made to ensure that high quality data are obtained in BOBMEX. The selection of the sensors/instruments for the surface observations, wherever possible, was made considering the Improved Meteorology (IMET) system developed by the Woods Hole Oceanographic Institution for application in the marine environment (Hosom et al. 1995). The makes of the sensors used for wind, precipitation, and radiation measurements (Table 1) included those selected for the IMET system. The relative humidity (humicap) and platinum resistance thermometer (PRT) sensors were calibrated in the laboratory before and after the field experiment using the same cables as those used on the ship. The radiation instruments were compared with the standards at the Central Radiation Laboratory, India Meteorological Department at Pune, and were found to maintain their original sensitivities. The Gill anemometer and sonic anemometer were tested in the wind tunnel at the Indian Institute of Science in the $4-15 \mathrm{~m} \mathrm{~s}^{-1}$ wind speed range and were found to be in excellent agreement with the wind tunnel data and with each other.

Further, intercomparison experiments were carried out at the TS1 location for about a 12-h duration at the start and end of the BOBMEX field phase to assess the relative accuracies of the data collected on two ships and buoy DS3. The data from intercomparison experiments showed consistency and good agreement between observations made from DS3, $S K$, and $S D$ (ICRP 2000). For example, Fig. 6a shows SST, wind speed, and water column temperature and salinity measured from the ships and the buoy on 27 August at TS1. SSTs shown are bucket SSTs for the ships (measured about $1 \mathrm{~m}$ below the surface) and those of the buoy are from a platinum resistance thermometer placed $3 \mathrm{~m}$ below the surface. The maximum difference in SSTs is $0.4^{\circ} \mathrm{C}$, with the average difference being less than $0.25^{\circ} \mathrm{C}$, the reading accuracy of the bucket thermometer. Wind speeds (reduced at 10-m height using Monin-Obukhov similarity profiles) agreed with each other within $1 \mathrm{~m} \mathrm{~s}^{-1}$. The turbulent nature of the wind and the spatial separation (ships and the buoy were $5-15 \mathrm{~km}$ apart owing to safety considerations) contributed to the differences, as did instrument differences. There is good agreement between the water column temperatures measured by CTDs from ships, especially in the mixed layer and in the upper thermocline. There is also broad agreement in the salinity data, which improved after subjecting the $S D$ salinity data to spike removal and other standard quality control operations.

Also, data from different instruments measuring the same variable on the ship have been intercompared. For example, in Fig. $6 \mathrm{~b}$ the air temperature $\left(\mathrm{T}_{\mathrm{a}}\right)$, specific humidity $\left(\mathrm{q}_{\mathrm{a}}\right)$, and horizontal wind speed $(\mathrm{U})$ are compared. The data for the sensors mounted on the boom and shown in Fig. $6 \mathrm{~b}$ are 10-min averages calculated from the continuous data sampled at $10 \mathrm{~Hz}$ for the sonic anemometer, Gill anemometer, and IR hygrometer, and $1 \mathrm{~Hz}$ for the PRT and humicap sensors (Table 1 ). The metkit data are typically $2-3-\mathrm{min}$ averages. The metkit wind speed has been reduced to 11.5-m height (mean height of wind sensors on the boom) using the Monin-Obukhov similarity profiles (Liu et al. 1979). Observed mean and rms differences for the period are shown in Table 3. The sonic anemometer measures the virtual temperature $\left(T_{v}\right)$, while the humicap measures the relative humidity (RH). Air temperatures from sonic anemometer data and specific humidity from humicap data are obtained by iteration.

It is observed from Fig. $6 \mathrm{~b}$ that air temperatures measured from PRT, sonic anemometer, and metkit are in broad agreement with each other. The metkit temperature shows a large diurnal amplitude compared to PRT and sonic temperatures, reflecting the partial effect of the ship deck (which responds more quickly to radiative heating/cooling) on the metkit temperature. PRT temperature shows a slightly larger diurnal variation (on 22 and $23 \mathrm{Aug}$, in particular) compared to the sonic anemometer air temperature. Perhaps this is due to the influence of the radiation shield inside which the PRT was placed. Good agreement is observed for the specific humidity also. Calibrations using the standard salt solutions confirmed that the humicap RH is accurate within $2 \%$ in the $70 \%-90 \%$ $\mathrm{RH}$ range. This corresponds to about $0.5 \mathrm{gm} \mathrm{kg}^{-1} \mathrm{un}-$ certainty in the mixing ratio. IR hygrometer and humicap data are within this range for the majority of the time. Sudden increases in IR hygrometer humidity are occasionally seen. The IR hygrometer is based on the principle of absorption of infrared radiation by the water vapor in a small volume of air. Its readings are not accurate when water droplets are present in the sampling volume, for example, when it was raining on 20 and 22 August. If such periods are not considered, then the mean difference between the humicap 

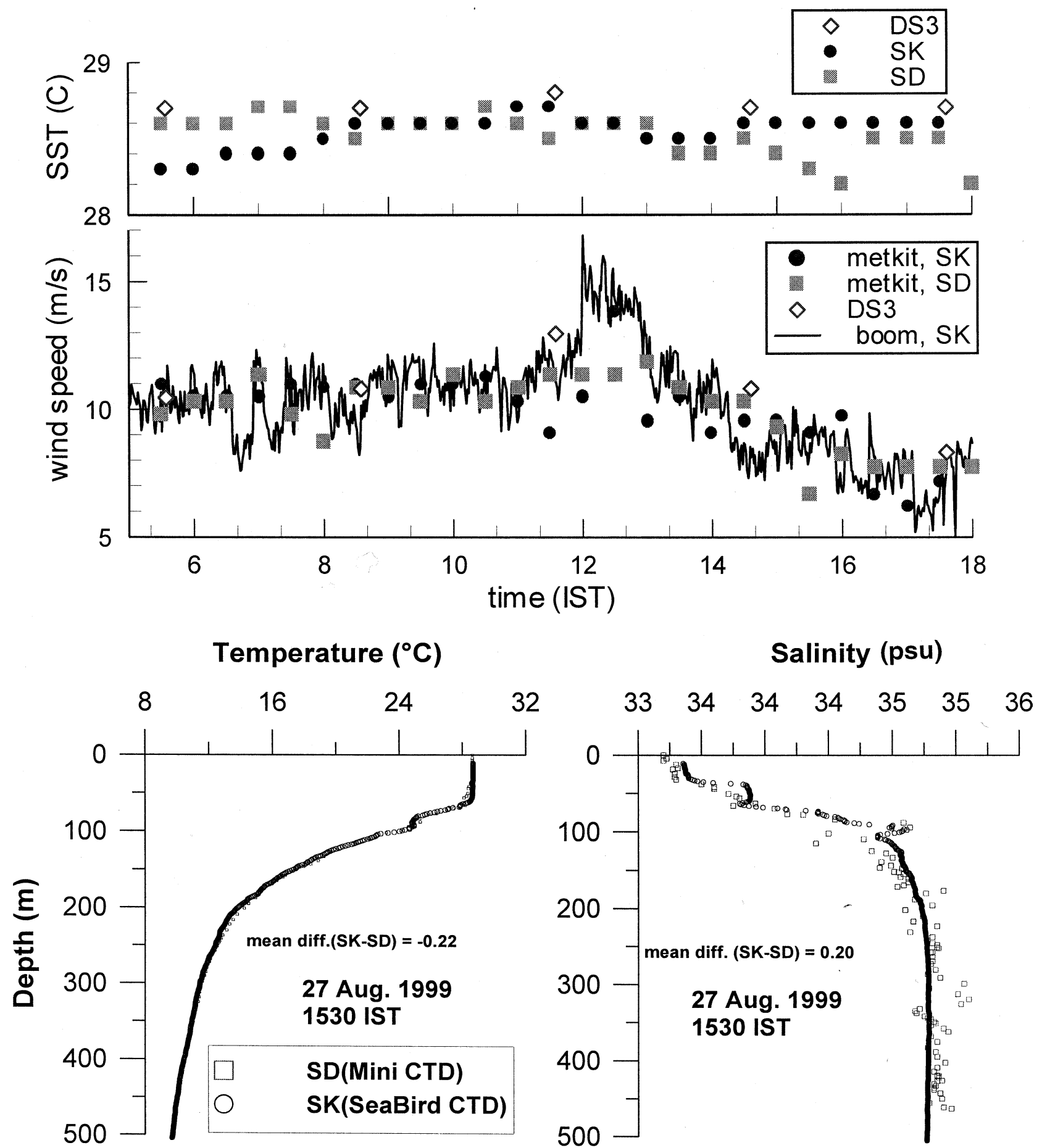

FIG. 6a. Comparison of SST (top) and wind speed (middle) measured from SK, SD, and DS3 on 27 Aug 1999 (IST: Indian standard time.) The wind speeds shown are calculated at 10-m height using Monin-Obukhov similarity profiles. SST on DS3 was measured at 3-m depth, and from $S K$ and $S D$ around 1-m depth. (bottom) Ocean temperature and salinity profiles measured from $S K$ and $S D$.

and IR hygrometer specific humidities is $0.1 \mathrm{gm} \mathrm{kg}^{-1}$ and the rms difference is $0.3 \mathrm{gm} \mathrm{kg}^{-1}$ (Table 3). The metkit mixing ratio is also in good agreement with the humicap data. There is excellent agreement between the wind speeds (corrected for the ship drift) measured by the sonic and Gill anemometers (average and rms differences are 0.1 and $0.3 \mathrm{~m} \mathrm{~s}^{-1}$, respectively; Table 3). The metkit wind speed is $1 \mathrm{~m} \mathrm{~s}^{-1}$ larger in the mean. This difference is probably due to the acceleration of the air caused by the ship structures that 

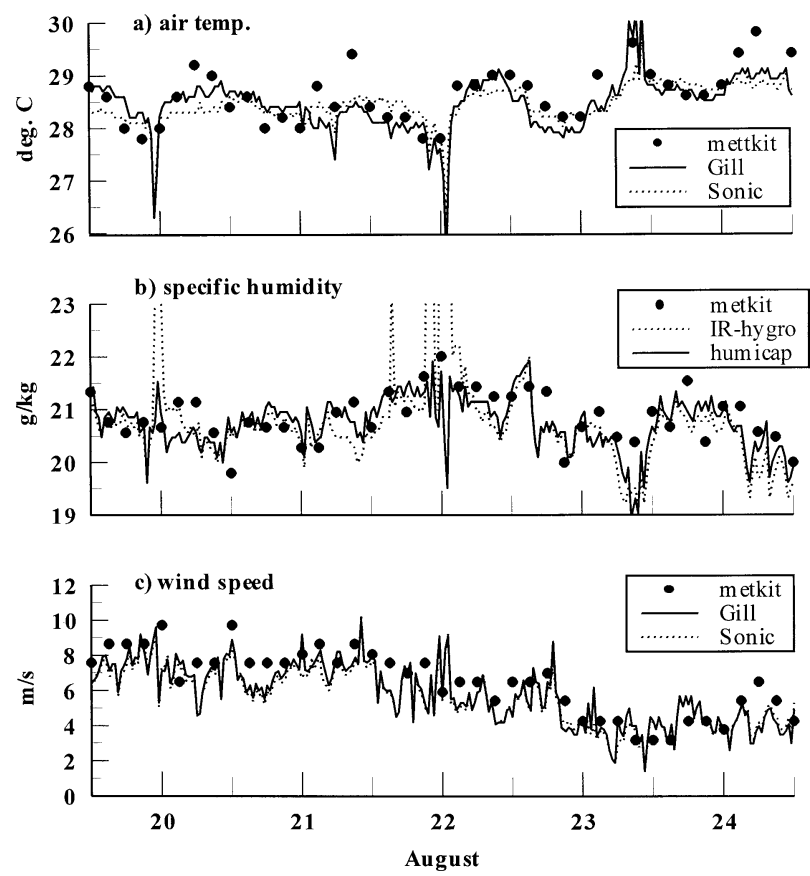

FIG. 6b. Comparison of air temperature, specific humidity, and wind speed measured at TS2 on board RV Sagar Kanya. See Table 1 for sensor details.

surrounded the open space where metkit observations were taken (Fig. 5b).

The measurement accuracies achieved on RV Sagar Kanya met the accuracy levels of $0.25^{\circ} \mathrm{C}$ and $0.2 \mathrm{~m} \mathrm{~s}^{-1}$ (or $2 \%$, whichever is larger) sought by the World Ocean Circulation Experiment (WOCE) program for air temperature and wind speed, respectively, for observations over the oceans (e.g., Hosom et al. $1995)$. The uncertainty in the relative humidity is $2 \%$ ( $0.5 \mathrm{gm} \mathrm{kg}^{-1}$ in mixing ratio), which is marginally higher than the WOCE requirement of $1.7 \%$.

\section{Variation of convection over the bay and surface variables during the BOBMEX field phase}

The variation of the OLR derived from INSAT for the grid boxes in the northern and southern bay where time series observations were carried out during the BOBMEX field phase is shown in Fig. 7. The SST and wind speed measured from the buoys are also shown in Fig. 7. Comparison with Fig. 4 shows that the variation of OLR in 1999 is characterized by a smaller timescale than that in 1998. It is seen that in 1999, over the northern and southern bay, there were several active spells with low OLR occurring at in- tervals varying between 5 and 9 days. The duration of each of these spells varies from 2 to 5 days. Between these active spells there are spells with almost cloudfree conditions, that is, with high OLR, which last for 2-7 days. As in 1998, the phases of decreasing (increasing) OLR are generally associated with decreasing (increasing) SST. The exception is the period 6-9 August, in which SST hardly changed, although there were large variations in OLR. This is similar to the event during 1-7 August in 1998 (Fig. 4b) in which the SST remained relatively steady. We return to a discussion of these events later in this section. Also note that the amplitude of variation of the SST in 1999 is much smaller than that in 1998. An important question to address in future studies is understanding why there was such a large difference in SST variations between the two monsoon seasons over the bay.

In active spell I (Fig. 7a), a low pressure system was generated in the north bay on 25 July, intensified into a depression on 27 July, and crossed over to land (Fig. 1a). Active spell II was associated with the genesis of a cloud band near $15^{\circ} \mathrm{N}$ in the eastern bay that extended up to the Indian coast at $20^{\circ} \mathrm{N}, 86^{\circ} \mathrm{E}$ on 1 August. The monsoon low seen in Fig. 1a during 25 August is associated with this disturbance. In spell III, a cloud band was generated on 4 August around $15^{\circ} \mathrm{N}$ that moved northward and intensified on 6 August (Fig. 8a), crossed the Indian coast on 7 August, and developed into a depression over land (Fig. 1a). Following this, a weak phase of convection prevailed over the bay during 9-13 August. Then a cloud band was generated around $16^{\circ} \mathrm{N}$ on 14 August,

TABLE 3. Comparison of surface air temperature, specific humidity, and wind speed at TS2 during 19-24 Aug 1999.

\begin{tabular}{lccc}
\hline \hline Variable & Average & Bias & Rms \\
\hline Air temperature $\left({ }^{\circ} \mathrm{C}\right)$ & 28.4 & & \\
$\quad$ Sonic and PRT & & $<0.1$ & 0.3 \\
Sonic and metkit & & 0.3 & 0.5 \\
\hline Wind speed (m s$\left.{ }^{-1}\right)$ & \multirow{2}{*}{5.7} & & \\
Sonic and Gill & & 0.1 & 0.3 \\
Sonic and metkit & & 1.0 & 1.0 \\
\hline Mixing ratio (g kg $\left.{ }^{-1}\right)$ & \multirow{2}{*}{20.7} & & \\
Humicap and IR hygro & & 0.1 & 0.3 \\
Humicap and metkit & & 0.1 & 0.4 \\
\hline
\end{tabular}


(a)
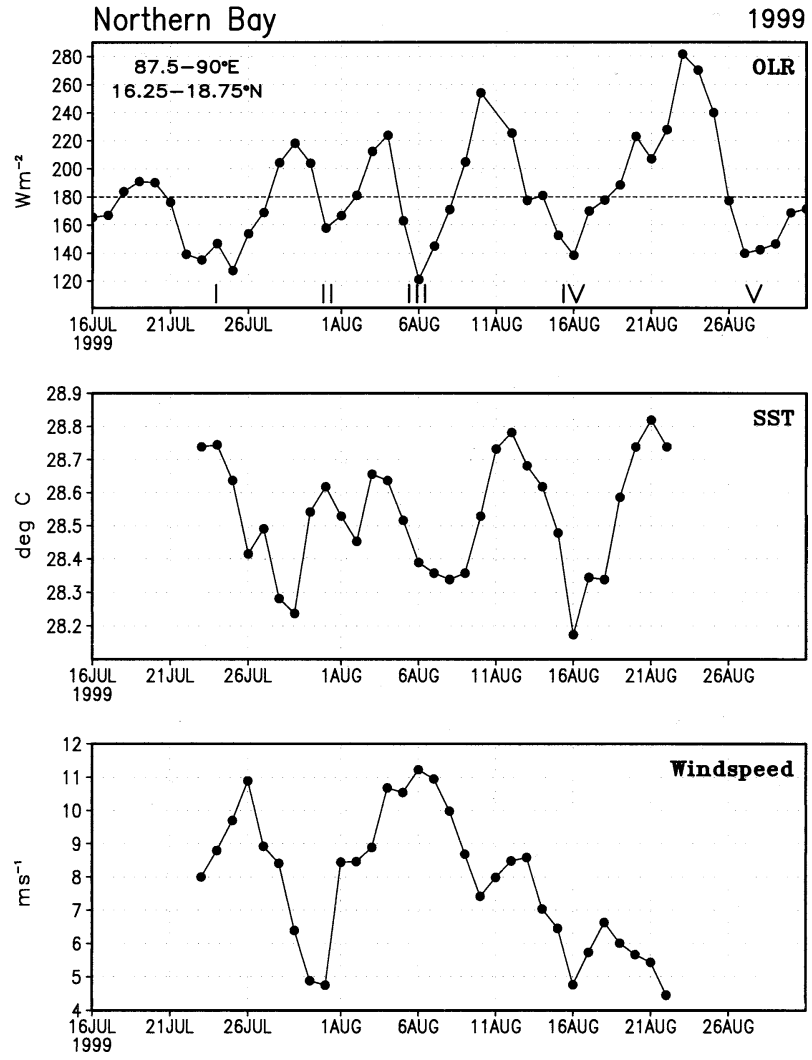

(b)
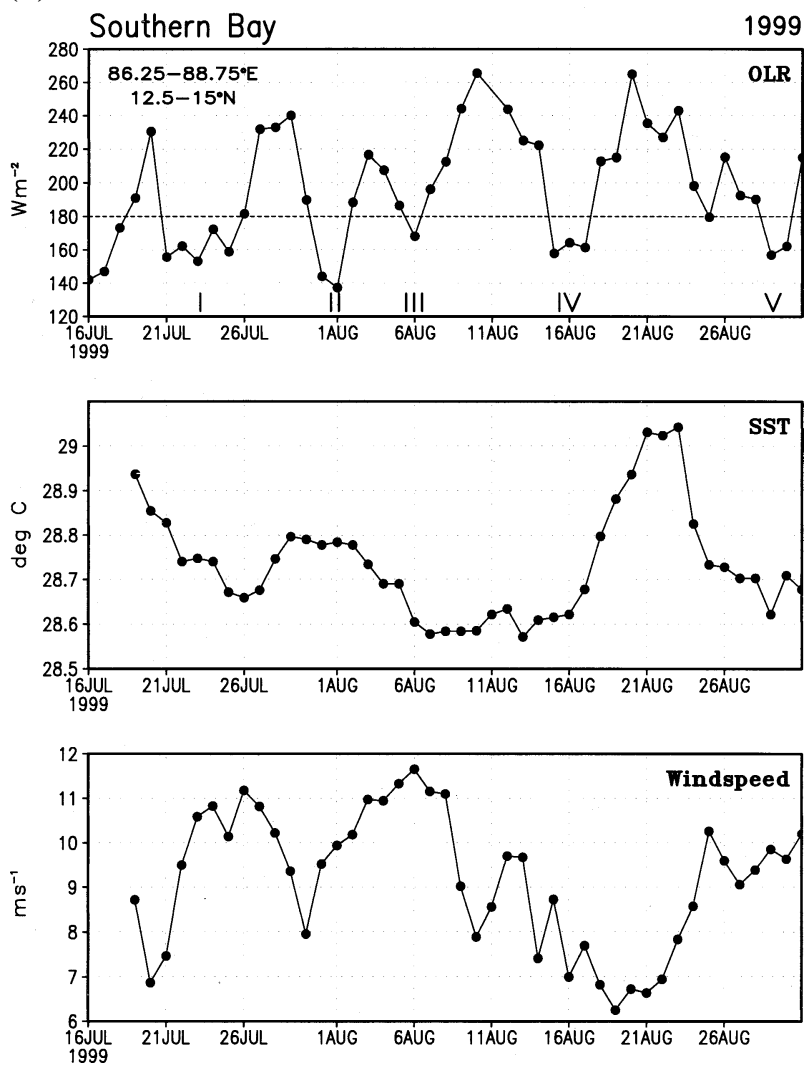

FIG. 7. Variation of INSAT OLR, buoy SST, and wind speed during Jul-Aug 1999. Active spells with OLR values below $180 \mathrm{~W} \mathrm{~m}^{-2}$ are marked by roman numerals. (a) North bay; (b) south bay.

which dissipated on the sea itself on 16 August. Again, clear sky conditions occurred over the bay during 1923 August (Fig. 8b). Finally, a low pressure area was generated over south-central bay on 24 August that moved northward and crossed land on 27 August. This event (marked as spell V in Fig. 7) was associated with considerable northward movement of the disturbance formed over the central bay (Fig. 1a). Thus, all the monsoon lows and depressions over the Indian subcontinent during the BOBMEX period had their origin over the bay. It may also be noted that, while three monsoon systems formed during 25 July-8 August (a duration of about 2 weeks), no monsoon system formed during the next 2 weeks (9-23 Aug). Thus a quasi-biweekly variation between active and weak phases of convection occurred during BOBMEX. We next consider the variation of surface fields in association with active and weak spells.

The Sagar Kanya was positioned at TS2 from 27 July to 24 August 1999 with a break (port call) during 6-12 August (Fig. 9). Henceforth, the periods 27 July-6 August and 13-24 August are referred to as leg 1 and leg 2, respectively, for the convenience of reference. The OLR, daily cumulative rainfall, SST, sea surface salinity (SSS), surface pressure, and wind speed measured in the northern bay are shown in Fig. 9. It is seen from Fig. 9 that, as expected, the major rainfall events of 1, 6, and 15 and 16 August over the north bay are associated with troughs in OLR with values ranging from 120 to $160 \mathrm{~W} \mathrm{~m}^{-2}$. SST tends to decrease in high rainfall spells. During 31 July1 August the TS2 station received about $80 \mathrm{~mm}$ of rainfall and SST decreased by about $0.4^{\circ} \mathrm{C}$. A larger decrease was observed during 15-17 August when the TS2 received about $200 \mathrm{~mm}$ of rainfall. SST increased after the rain events. The SST increased by more than $1{ }^{\circ} \mathrm{C}$ during 19-24 August, a period characterized by high values of OLR and low wind speed. Note that the observed surface pressure and wind speed from the ship and buoy are rather close. However, the SST measured from the ship does differ from that measured from the buoy by as much as $0.5^{\circ} \mathrm{C}$ on some days. In particular, during and after the high rainfall events of 1 August and 15 and 16 August, the SST at TS2 
decreased much more than that at DS4. This could have arisen from differences in the intensity of convection (and its effects) between the two locations, which are separated by about $120 \mathrm{~km}$.

The SSS rapidly decreased by about 4 psu (practical salinity unit) during 27 July-3 August at TS2. This decrease was most probably caused by advection of freshwater from the north. Thereafter, it increased gradually till 5 August. After that, for about a day, the SSS increased rapidly. The SSS reached above $31 \mathrm{psu}$ on 6 August but rapidly decreased to below 30 psu thereafter following heavy rain. Processes responsible for this rapid rise and fall of SSS are being investigated. Unfortunately the ship had to leave TS2 for a port call at this critical juncture. The SSS was again lower than 28 psu when observations were resumed at TS2 on 13 August. During 14-24 August, SSS increased gradually by about 1 psu.

At TS1 observations were made by $S D$ during 16 July-29 August with breaks during 22-30 July, and 5-12 and 16-25 August for port calls. The buoy DS3 provided continuous time series data at TS1. The conditions at TS1 in the southern bay are shown in Fig. 10. The SST at TS1 decreased by about $0.3^{\circ} \mathrm{C}$ in the first active spell (21-23 Jul), increased by about $0.2^{\circ} \mathrm{C}$ during the following weak spell, and by $0.5^{\circ} \mathrm{C}$ in the weak spell between 18 and 23 August. In the weak spell during 7-13 August the SST hardly changed. It is interesting to note that SSS increased by almost 1 psu at the beginning of this spell and decreased toward the end of the spell. The relatively steady SST with increasing SSS in this period could arise from enhanced evaporation, vertical mixing, or advection of cooler and more saline water. The relative importance of these factors in determining the variation of SST has to be assessed with the analysis of surface fluxes, current data, and mixed layer heat and salt budgets. A more gentle increase of similar amplitude is also seen toward the beginning of the weak spell of 18-23 August. At TS1, the fluctuations in SSS are of smaller amplitude, less than 1 psu compared to 4 psu at TS2. We return to a discussion of the salinity changes at these two locations in section 7.

It is seen from Fig. 9 that the surface pressure at TS2 fluctuated about a relatively low value ( $\sim 999 \mathrm{mb})$ in the first 2 weeks of observation and then was maintained at a higher value $(\sim 1006 \mathrm{mb})$ in the last 2 weeks. During the corresponding period, the average surface pressure at TS1 (southern bay) also increased from a lower $(\sim 1004 \mathrm{mb})$ to higher $(\sim 1007 \mathrm{mb})$, value, but (a)

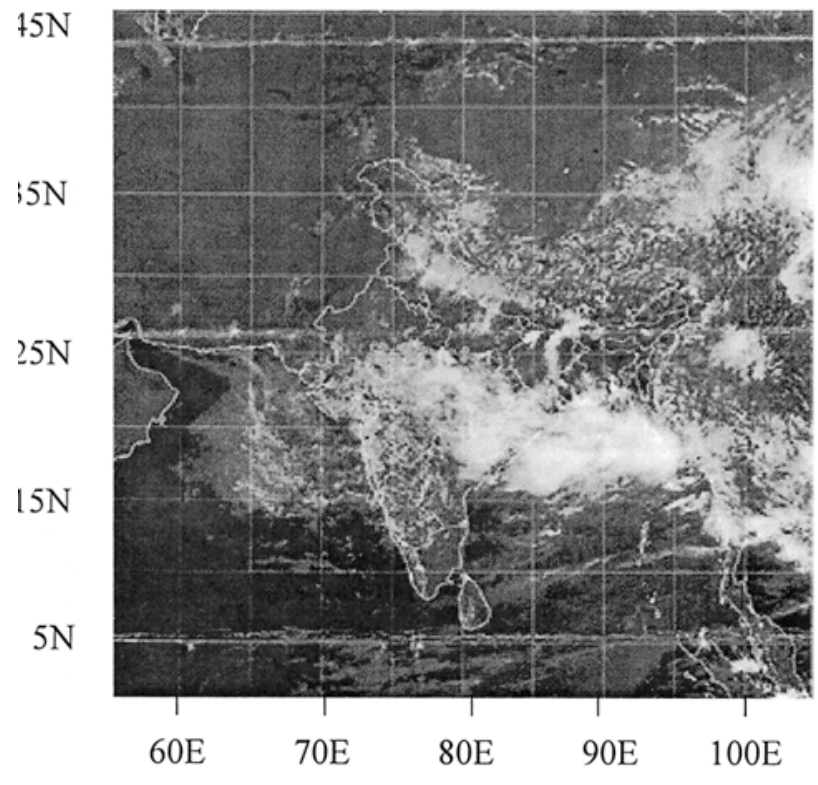

(b)

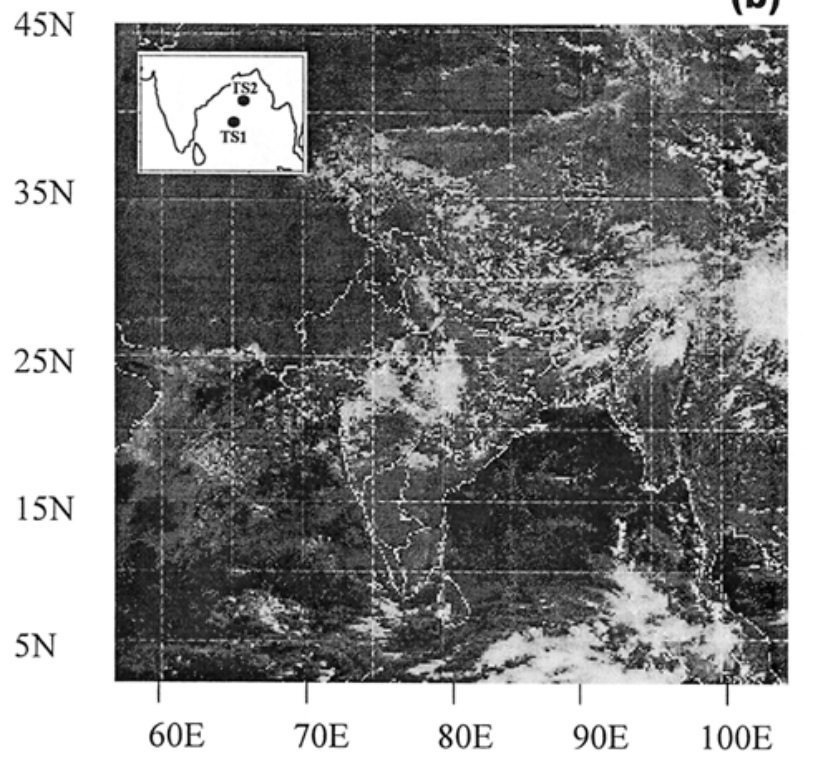

FIG. 8. 0600 UTC INSAT visible imagery: (a) 6 Aug and (b) 21 Aug 1999.

the amplitude was smaller. The OLR also exhibits this quasi-biweekly oscillation with low values occurring more frequently in the first 2 weeks. Over the bay region, spatially extensive deep cloud cover characterized the first phase (Fig. 8a) while almost clear sky conditions characterized the second phase (Fig. 8b). Thus, the BOBMEX observation period covered active and weak phases of the intraseasonal variation over the bay. Further analysis of the large-scale dynamics as well as the surface fluxes (e.g., Shinoda et al. 1998) are expected give some insight into this variation. 

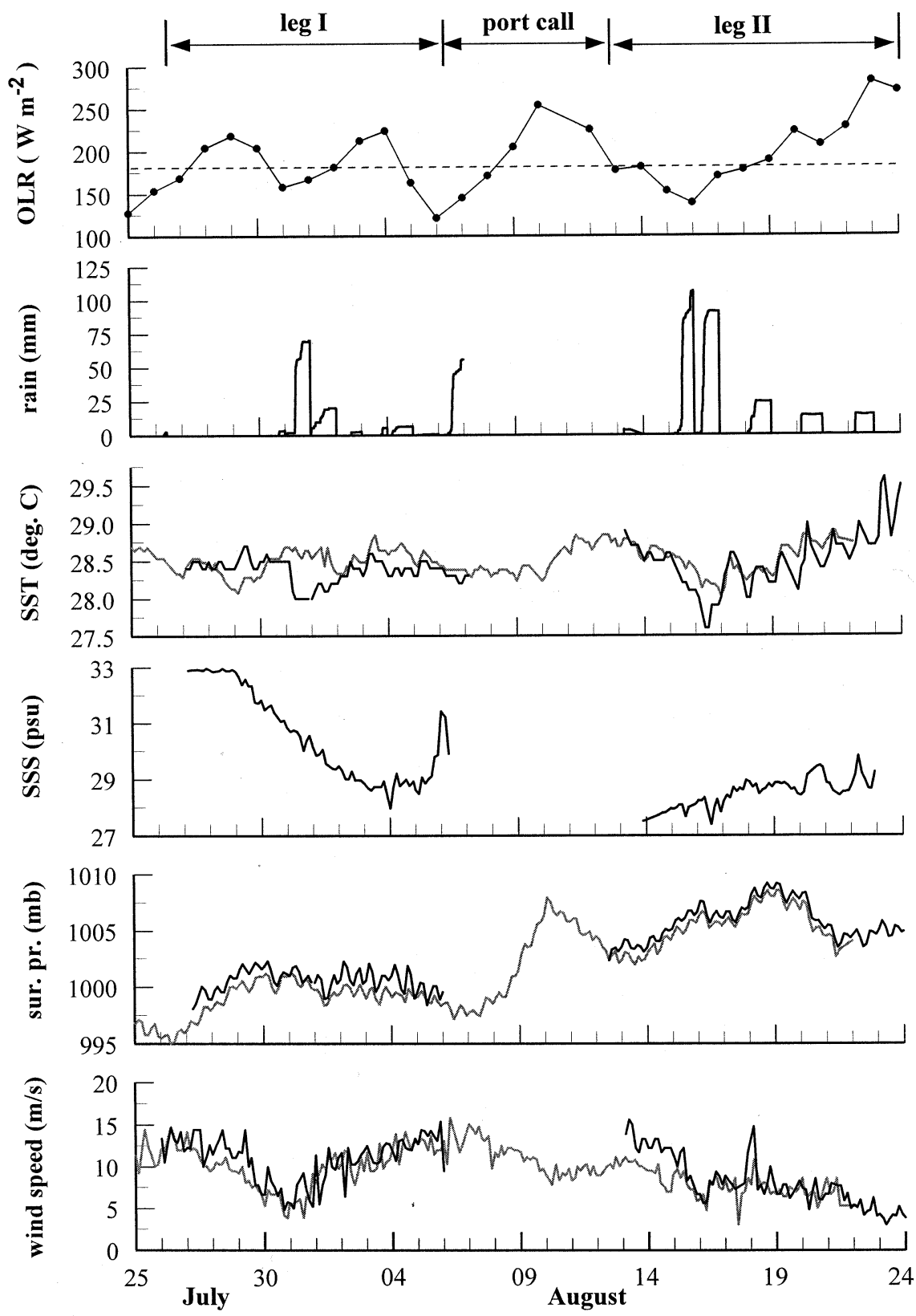

FIG. 9. Variation of INSAT OLR, daily cumulative rainfall starting from local midnight, SST, SSS, surface pressure, and wind speed in the north bay during BOBMEX. Darker and lighter lines refer to observations at TS2 and DS4, respectively. During the periods marked leg 1 and leg 2, RV Sagarkanya was positioned at TS2. quency of launch varied between 2 and 5 day $^{-1}$ depending on the synoptic conditions and weather advice. Typical vertical resolution is $25 \mathrm{~m}$. During each launch, the radiosonde temperature, humidity, and pressure readings were compared with the ground truth and entered into the radiosonde receiver unit for corrections. Before corrections, radiosonde temperature, humidity, and pressure readings were within $0.2^{\circ} \mathrm{C}, 2 \%$, and $0.5 \mathrm{mb}$, respectively, from the ground truth. In the final output, the radiosonde processor adjusted the calibration constants to take care of these minor differences. Before each launch, the radiosonde humidity sensor was tested in a $100 \% \mathrm{RH}$ chamber. The RH measured by the radiosonde increased quickly to $90 \%$ within a few seconds and the response became slow above $95 \%$, but all radiosondes showed 98\%-100\% RH values after a few minutes. Since the differences between ground reference values and radiosonde-measured values were within the accuracy of the sensor, no corrections have been applied to the radiosonde RH data. We may expect a slight underestimation of water vapor amount if $\mathrm{RH}$ values of more than $95 \%$ occurred in a thin layer and the balloon passed through this layer before the sensor could fully respond.

Here we present the observa-

\section{Vertical variations in the atmosphere}

It was planned to collect data with high-vertical resolution radiosondes from both of the ships. However, unforeseen difficulties were faced in procuring radiosondes for one of the ships. Hence, radiosondes (Vaisala model RS80-15G) were launched only from $S K$. More than 90 ascents covering active and weak phases of convection are available. The fre- tions made from $S K$. Figure 11a shows one temperature profile each from the active and weak phases of convection at TS2. The temperature difference between convectively active and convectively weak atmospheres is typically less than $2^{\circ} \mathrm{C}$ except near the surface, whereas, humidity (dewpoint temperature) and wind fields exhibited larger fluctuations. Figure 11b shows the time-height variation of relative humidity. It is observed from Fig. 11b that the relative humid- 
ity was generally high throughout the troposphere during leg 1 as compared to that during leg 2. During 20-24 August (weak phase of convection), a low humidity regime gradually moved down from around the $350-\mathrm{mb}$ level ( 9 km) to $600 \mathrm{mb}(\sim 4 \mathrm{~km})$, and the midtroposphere dried up.

Upper winds are available for the second leg of BOBMEX only. Figure $11 \mathrm{c}$ shows the vertical variation of wind from 13 to 30 August. The ship moved from TS2 to TS1 during 2427 August, and from TS1 to Chennai during 27-30 August. Therefore, these two periods correspond to meridional and zonal sections over the bay. The ship was in the outer periphery of the system that developed in the last week of August (Fig. 1a) and not much rainfall was observed from the ship. When a convective system was present nearby (e.g., 13-16 and 2528 Aug), wind speed increased around the 900-mb level and in the upper troposphere near the 200-mb level (Fig. 11c). During the weak convective period (2024 Aug), maximum winds were in the $25-30 \mathrm{~m} \mathrm{~s}^{-1}$ range, whereas winds in $35-44 \mathrm{~m} \mathrm{~s}^{-1}$ range prevailed during convectively active periods. Normally, low winds prevailed around the 500-mb level on all occasions. It is also seen from Fig. 11c that during weak convective conditions, low wind speed $\left(<10 \mathrm{~m} \mathrm{~s}^{-1}\right)$ prevailed from the surface to the $350-\mathrm{mb}$ level. At low levels, southwesterly winds prevailed, with the exception being the period around 26 August when they became southerly. At upper levels ( $200 \mathrm{mb}$ ), easterly winds are always present. During an active period, southwesterly winds penetrated beyond 300-mb height, whereas, as the weak convective conditions continued, easterly winds gradually migrated down to the 600 -mb level. In general, the change from southwesterly to easterly wind di- rection took place abruptly; that is, the transition was sharp.

The variation of the CAPE of the surface air ( $\sim 10 \mathrm{mb}$ above sea level) and average of the lowest 50-mb layer (referred to as the average of CAPE for convenience) are shown in Fig. 12a. Average CAPE is calculated by averaging the individual CAPE of air parcels lifted in 5-mb intervals. Also shown in Fig. 12a are SST and daily cumulative rainfall values recorded at TS2. It is observed from Fig. 12a that the CAPE of 


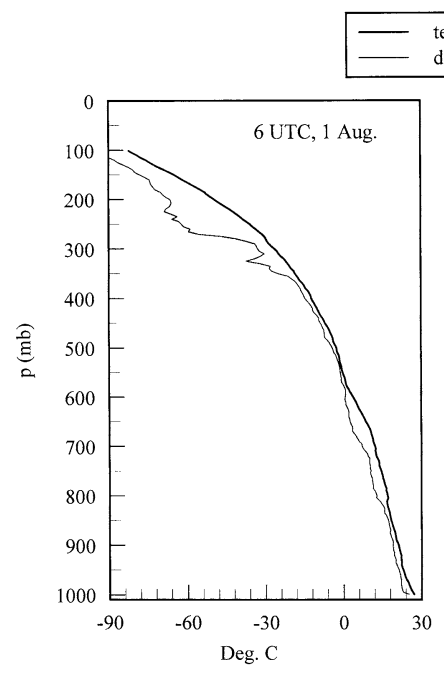

temperature

ew point

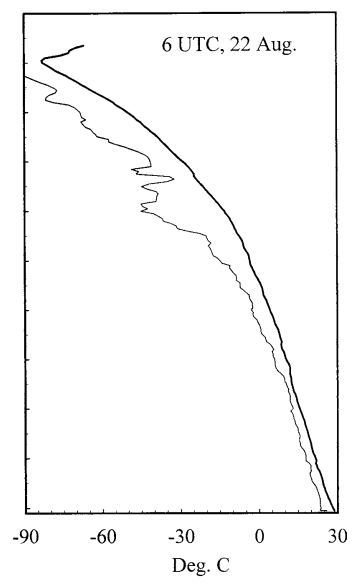

FIG. 11a. Vertical profiles of the atmosphere measured from $S K$. Air temperature and dewpoint temperature during active (1 Aug) and weak (22 Aug) periods of convection at TS2.

the surface air and the average CAPE exhibit similar temporal variation. The mean values of surface and average CAPE are around 3 and about $1 \mathrm{~kJ} \mathrm{~kg}^{-1}$, respectively. Values of CAPE are high before convection and low during the active phase, consistent with previous observations over the tropical oceans (e.g., Williams and Renno 1993). The range of CAPE values observed during BOBMEX are comparable to those observed over the west Pacific warm pool during TOGA COARE (Kingsmill and Houze 1999). The consumption of instability by deep convection, as measured by the decrease in the value of CAPE is $2-3 \mathrm{~kJ} \mathrm{~kg}^{-1}$ for the surface air and about $1 \mathrm{~kJ} \mathrm{~kg}^{-1}$ for the lowest $50-\mathrm{mb}$ layer. After the rains ceased, CAPE increased rapidly and more or less recovered to the preconvective values within 2 days. It is also observed that while SST increased from less than $28.5^{\circ} \mathrm{C}$ on 19 August to $29.5^{\circ} \mathrm{C}$ on 24 August, CAPE remained nearly a constant (in fact showed a marginally decreasing trend) during this period. Thus, a higher value of SST need not necessarily translate into enhanced atmospheric instability.

A superadiabatic layer was frequently observed near the surface and very often the air ascending from the surface (10-m level) had a positive buoyancy at the lifting condensation level. Hence CINE of the surface air was often zero (Fig. 12a). The maximum value of surface air CINE did not exceed $20 \mathrm{~J} \mathrm{~kg}^{-1}$. In general, the average CINE of the 50-mb layer decreased to values below $10 \mathrm{~J} \mathrm{~kg}^{-1}$ before the start of convection and increased during the rains.

Further insight into the changes in the lower troposphere is obtained from the time-height section of CAPE and CINE shown in Fig. 12b. Major features are similar during the evolution of the convective events. Consider, for example, the period around 15 August. Before the deep convection set in on 15 August, above the 875-mb level, CAPE was zero and CINE exceeded $50 \mathrm{~J} \mathrm{~kg}^{-1}$. During convection, while CAPE decreased at lower levels, there were layers between 850 and $700 \mathrm{mb}$ where it became positive. Also, the value of CINE in the corresponding layers decreased below $10 \mathrm{~J} \mathrm{~kg}^{-1}$. Thus, while only the lowest $0.5-1-\mathrm{km}$ layer was unstable during normal conditions, when deep convection set in, the lowest 3-km layer became unstable to moist convection. This means that convergence of air taking place in a deeper layer could feed

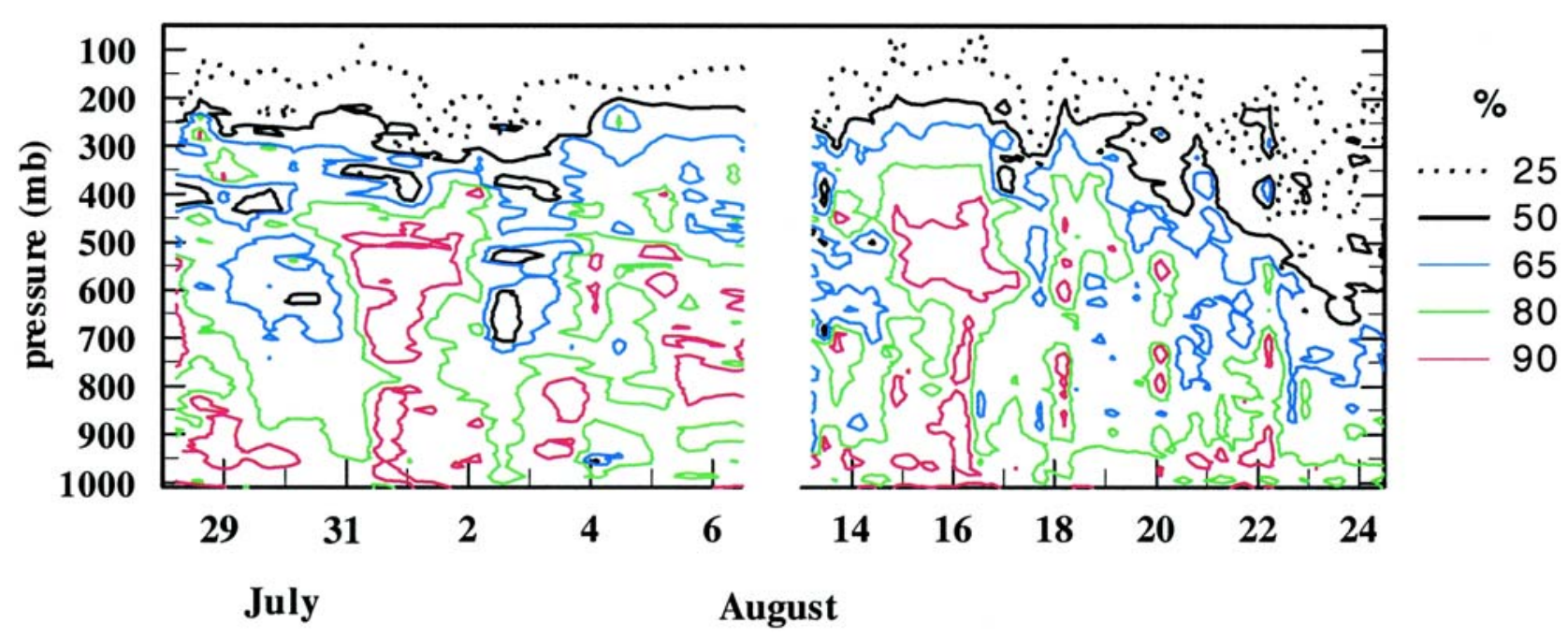

FIG. 11b. Vertical profiles of the atmosphere measured from $S K$. Time-height variation of relative humidity at TS2. 

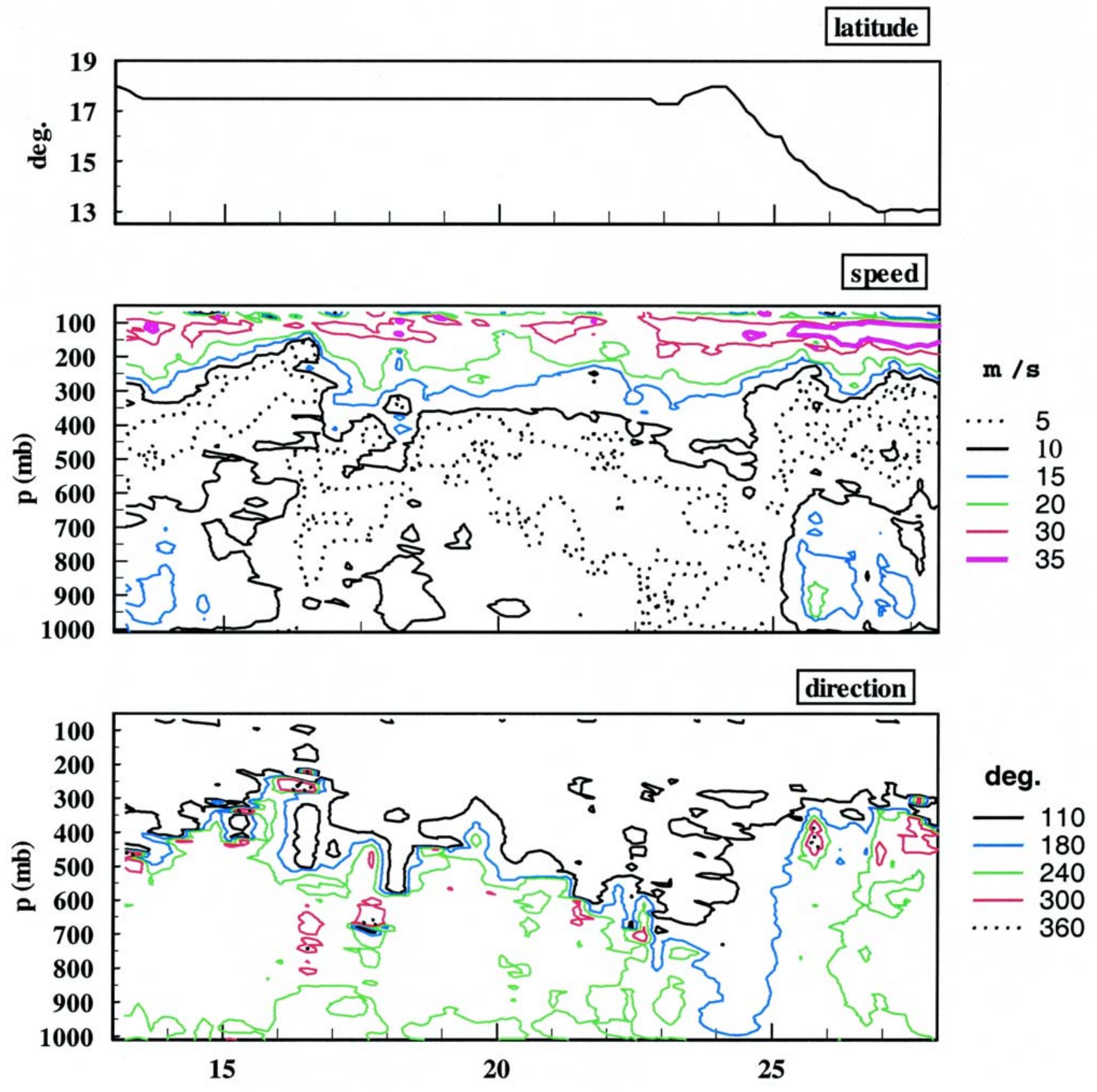

August

FIG. 11c. Vertical profiles of the atmosphere measured from SK. Time-height variation of wind speed and wind direction from 13 to 28 Aug. (top) Latitudinal position of the ship; the longitudinal position can be seen from Fig. $5 \mathrm{a}$.

clouds during the active phase of convection. During 17-23 August, the atmosphere returned to clear sky conditions, and gradual lowering of the top of the unstable layer below $925 \mathrm{mb}$ was seen and the value of CINE increased beyond $50 \mathrm{~J} \mathrm{~kg}^{-1}$ above $925 \mathrm{mb}$. The drastic reduction in the height of the unstable layer on 24 August (when SST was high) was probably due to the strong subsidence induced by the system that intensified in the south-central bay. After the ship moved away from this time series position, deep clouds were seen in the satellite imagery on 26 August.

\section{Thermohaline structure}

Temperature and salinity of the water column were measured every $3 \mathrm{~h}$ from $S K$ at TS2 from 26 July to 23 August with a break from 7 to 13 August. At TS1 

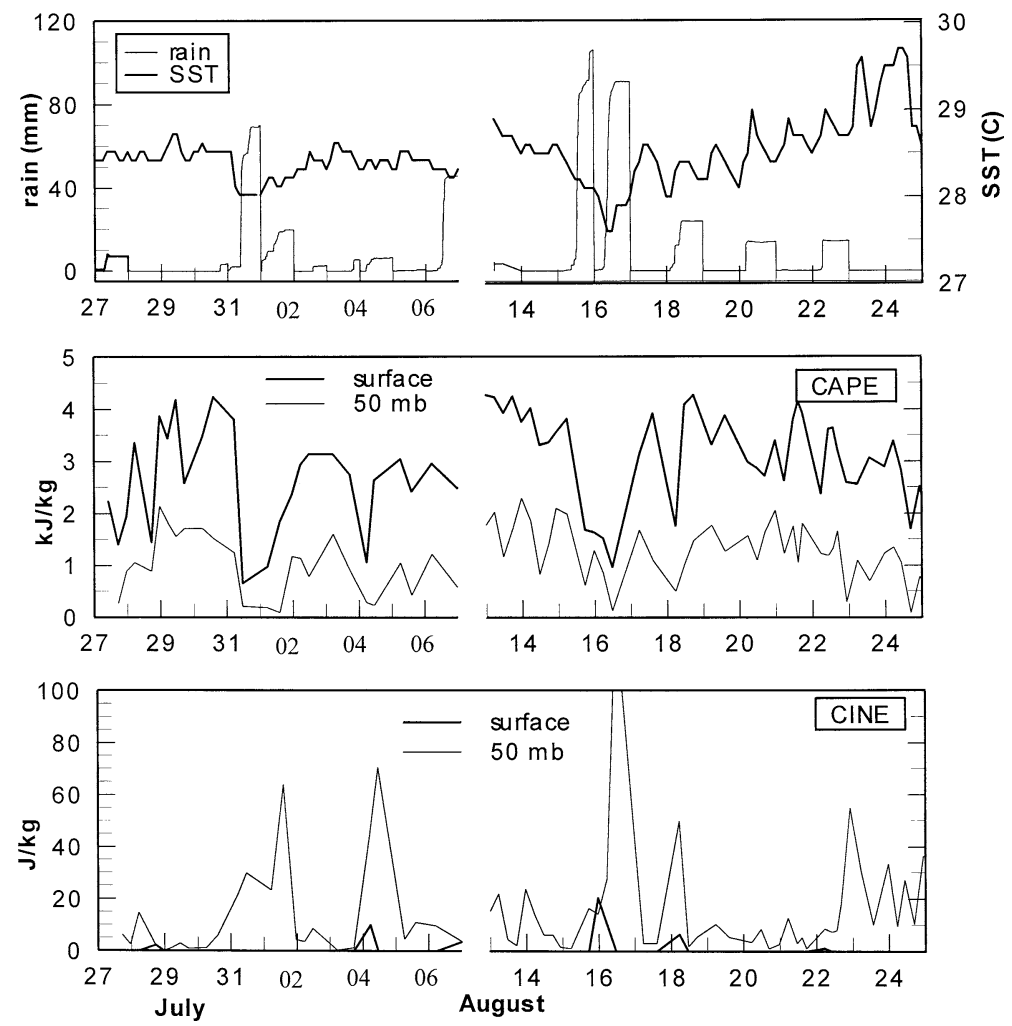

FIG. 12a. Variation of CAPE and CINE at TS2 for the surface air and that of the lowest 50-mb layer. Also shown (top panel) are SST and cumulative daily rainfall at $\mathrm{TS} 2$.

observations were made by $S D$ during 15 July29 August with breaks during 22-30 July, and 5-12 and 16-25 August for port calls.

\section{a. Vertical structure}

Based on the BOBMEX vertical profiles of temperature and salinity, the upper layer of the northern bay can be divided into three sublayers: the mixed layer, a barrier layer including one or more salt stratified layers, and the thermocline. An example of such a profile is shown in Fig. 13a. The uppermost layer is homogeneous in both temperature and salinity; in the second layer, the temperature gradient is small, but there is a well-marked gradient in salinity and hence density. Often the vertical gradient of salinity is not uniform but consists of several steps. Generally this layer has the same temperature as the surface mixed layer. Occasionally, there are differences of up to $0.5^{\circ} \mathrm{C}$ from the surface temperature. Below the barrier layer the temperature decreases rapidly and the salinity and density increase gradually.

The vertical structure at TS1 in the southern bay is different from that of the north bay. On some days, there is no barrier layer. On 18-19 July, for example, the upper layer is well mixed in temperature and salinity and about $60 \mathrm{~m}$ deep (Fig. 13b). However, on other days, such as 27 August, salinity effects can be seen clearly (Fig. 13c), with an upper isohaline layer and a halocline. Below the halocline the salinity is again uniform. For the profile shown in Fig. 13c, the salinity increases from $33.7 \mathrm{psu}$ at $30 \mathrm{~m}$ to $34.0 \mathrm{psu}$ at $38 \mathrm{~m}$ and then remains at 34.0 psu till the base of the isothermal layer.

\section{b. Mixed layer}

Various criteria can be found in the literature for determining the depth of the mixed layer in the tropical oceans (Anderson et al. 1996). Historically the base of the mixed layer has been taken as the depth at which the temperature changes from its surface value by $1^{\circ} \mathrm{C}$ (sometimes $0.5^{\circ} \mathrm{C}$ ). Using the $1^{\circ} \mathrm{C}$ criterion Rao et al. (1989) calculated the climatological monthly mean mixed layer depths in the north Indian Ocean. Using CTD observations Shetye et al. (1996) found that the wintertime surface layer in the bay that is homogeneous in both temperature and salinity is much shallower than the depth obtained by Rao et al. (1989). The reason for this discrepancy was attributed to salinity effects, which were not considered by Rao et al. (1989). Murty et al. (1996) observed that during the summer monsoon the mixed layer in the northern bay is shallower than the isothermal layer. The barrier layer was observed first in the western equatorial Pacific Ocean (Lukas and Lindstrom 1991). The seasonal evolution of barrier-layer thickness in the global Tropics is documented in Sprintall and Tomczak (1992). We define the mixed layer depth as the depth at which the vertical gradient of density exceeds $0.05 \mathrm{~kg} \mathrm{~m}^{-4}$. The CTD data spaced at $1-\mathrm{m}$ interval were scanned downward and the uppermost depth where the above criterion is satisfied was chosen as the mixed layer depth. For the profile shown in Fig. 13a, for example, the mixed layer depth is $14 \mathrm{~m}$, whereas the isothermal layer is $33 \mathrm{~m}$ deep. The mixed layer depth shows considerable variation with time and space depending on the surface conditions such as wind speed and freshwater content. In general, the southern bay has deeper 

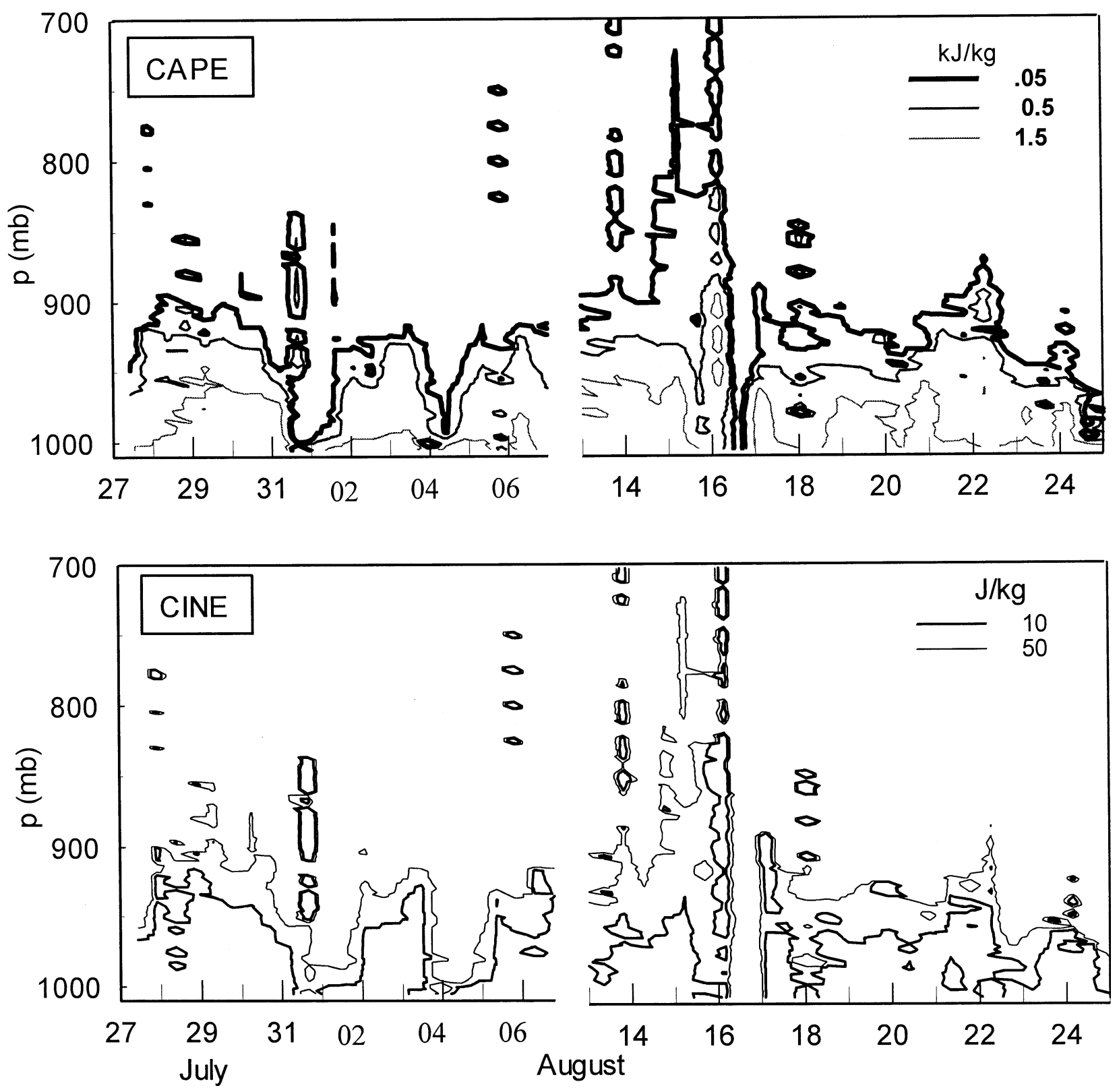

FIG. 12b. Time-height variation of CAPE and CINE at TS2.

isothermal and mixed layers than in the north. When salinity effects are present the base of the mixed layer shallowed from 60 to $30 \mathrm{~m}$ (Fig. 13c). The temperature of the mixed layer does not show much variation; it remains close to $28.5^{\circ} \mathrm{C}$ during most of the observation period. [This is consistent with the climatological annual cycle of SST in the bay, which shows a "plateau" during the summer monsoon (Vinayachandran and Shetye 1991).]

The time evolutions of the upper-layer temperature and salinity at TS2 and TS1 are presented in Figs. 14 and 15, respectively. In comparison with
TS2, the surface waters at TS1 are more saline. Salinity effects are of utmost importance in the northern bay. A strong halocline is present throughout the summer monsoon that often reduces the mixed layer thickness to less than $10 \mathrm{~m}$. It is reasonable to assume that the strong halocline in the north bay is maintained by the advection of freshwater of riverine origin, and rain. The salinity of the upper layer at TS2 decreased till about 13 August, except for the rapid changes during 5 and 6 August (section 5), and increased slightly thereafter. At TS1, tha salinity of the upper layer appears to have increased throughout. The ha- 

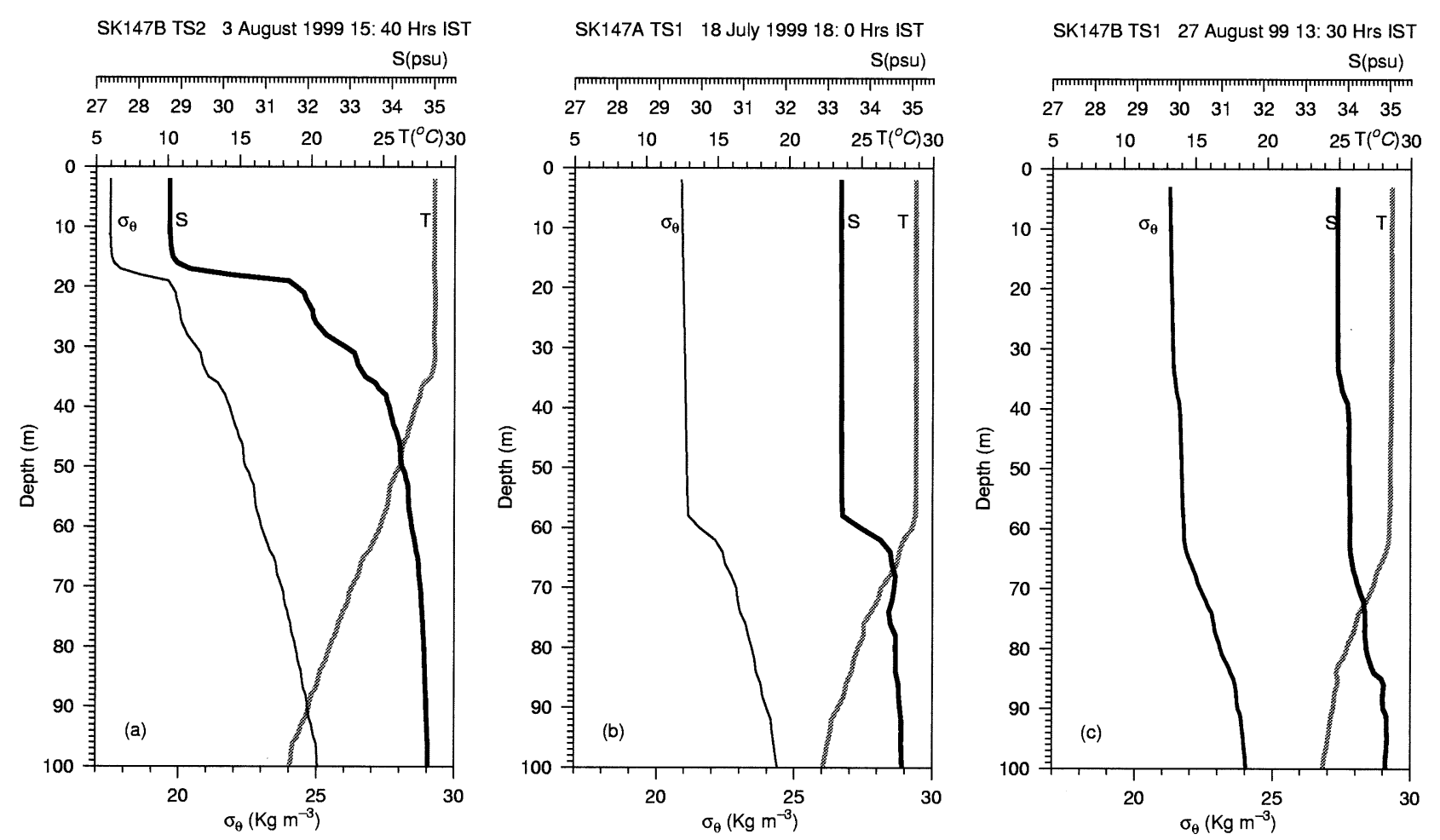

FIG. 13. Vertical profiles of temperature $(T)$, salinity $(s)$, and density $\left(\sigma_{\theta}\right)$ from CTD measurements from ORV Sagarkanya: (a) TS2 at 1540 IST 3 Aug, (b) TS1 at 1330 IST 18 Jul, and (c) TS1 at 1330 IST 27 Aug.

locline is very sharp and restricted to about $30 \mathrm{~m}$, whereas the thermocline occurs over a deeper layer. This halocline is very tight during the first half of the observation period but broadens afterward, indicating the weakening salinity effects on the upper layer. There appears to be an increase in the depth of the halocline during 6-12 August. However, data are not available during this period as the ship had to go for a port call.

\section{c. Comparison with the west Pacific}

A large number of convective systems form over the western equatorial Pacific Ocean (Godfrey et al. 1998) and over the Bay of Bengal (Fig. 1a). Consequent to freshwater input by rainfall, the upper-layer salinity decreases in both cases. The major features of the interaction of the west Pacific with the atmosphere are 1) a decrease of the salinity of the upper layer consequent to freshwater input from rainfall, resulting in the formation of a thin surface layer that floats over the thermally mixed layer; 2) restriction of the air-sea interaction to this layer under conditions of weak wind because the barrier layer inhibits exchange with the water below; and 3) breaking of the barrier layer with the occurrence of a strong wind event leading to a profile with a mixed layer that is homogeneous in temperature and salinity, like the one existing before the rain event. An important question to address is, do similar events characterize the airsea interaction over the bay?

The observations during BOBMEX suggest that the scenario in the northern bay is rather different from that in the west Pacific. First of all, the salinity of the upper layer in the northern bay is several practical salinity units less, which makes the surface water in the bay much lighter. Compared to the west Pacific salinity of about $34 \mathrm{psu}$, the surface salinity in the north bay can become as low as 28 psu (e.g., Fig. 9). Second, the halocline that is located at the base of the surface mixed layer in the bay is much stronger than that in the west Pacific. Lukas and Lindstrom (1991) observed a vertical salinity gradient of $0.01 \mathrm{psu} \mathrm{m}^{-1}$ and this halocline was located in about 30-m-depth range. It is clearly seen from Fig. 13 that the halocline at TS2 is much stronger and often occurs at a much shallower depth. We believe that the strong multiple haloclines in the northern bay observed during BOBMEX have not been reported previously. The barrier layer in the west Pacific is destroyed by a westerly wind burst. The mean strength of these westerly winds is $10 \mathrm{~m} \mathrm{~s}^{-1}$ 

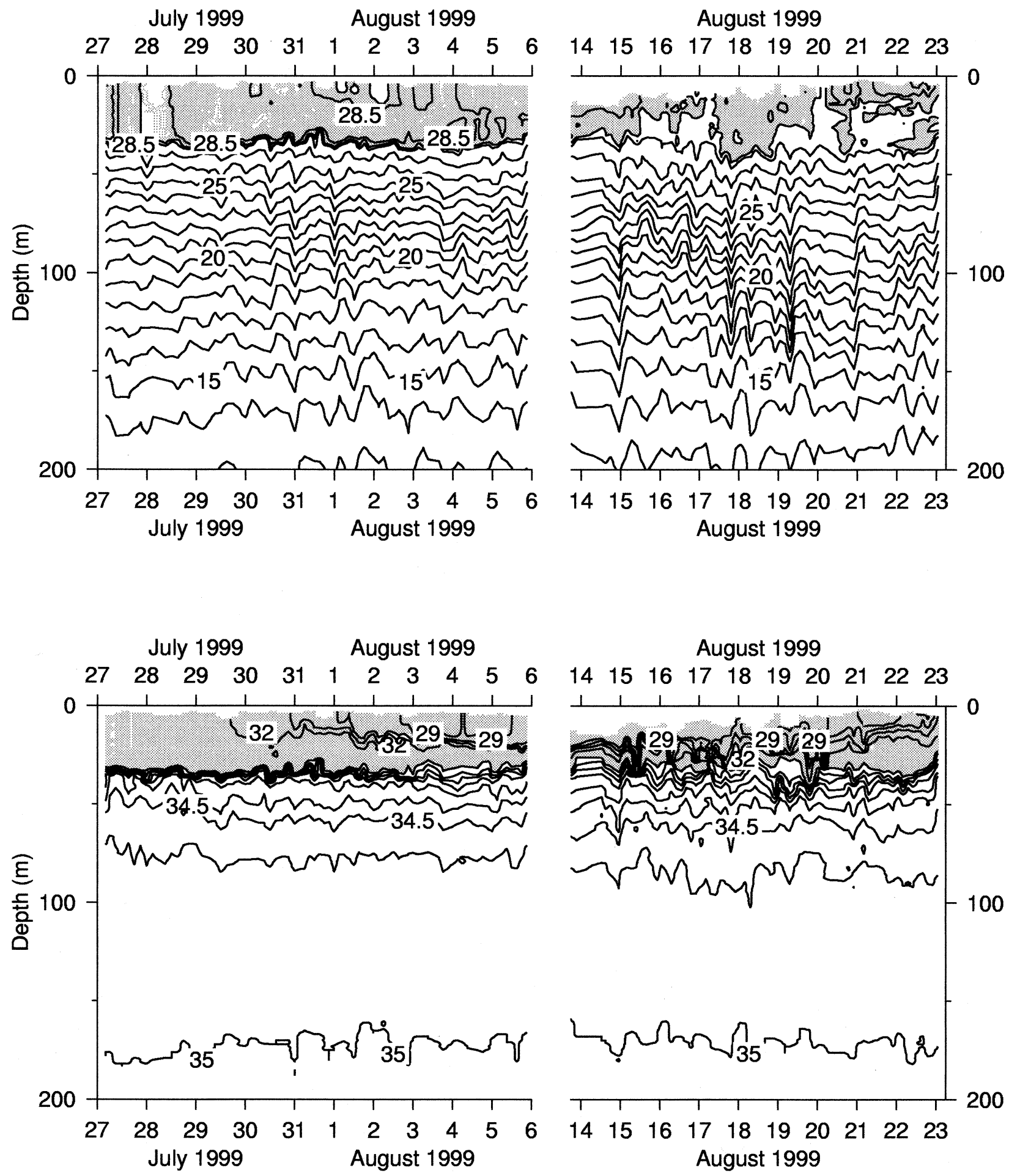

FIG. 14. Time-depth section of temperature (top) and salinity (bottom) at TS2. Contour interval for isotherms greater than $28.5^{\circ} \mathrm{C}$ is $0.25^{\circ} \mathrm{C}$ and for less than $28^{\circ} \mathrm{C}$ it is $1^{\circ} \mathrm{C}$. Regions with temperatures greater than $28.5^{\circ} \mathrm{C}$ are shaded. Contour interval for salinity is 0.25 psu throughout the water column. Regions with salinity less than 33 psu are shaded.

(Godfrey et al. 1998). In the northern bay the winds exceed this value on several occasions during the summer monsoon (Fig. 9). Despite the strong winds, it was observed during BOBMEX that once it is formed the barrier layer can persist, perhaps throughout the monsoon.

The southern bay, however, appears to be more similar to the west Pacific. On some days, the shape 

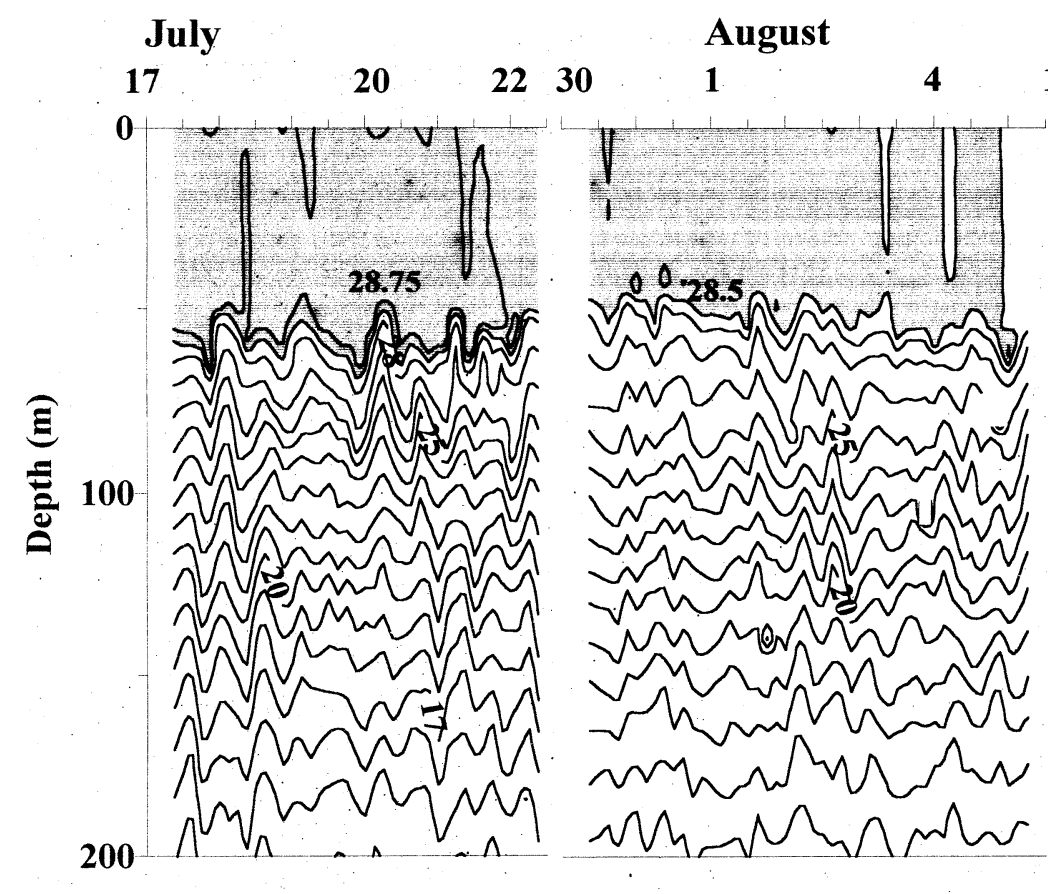

12

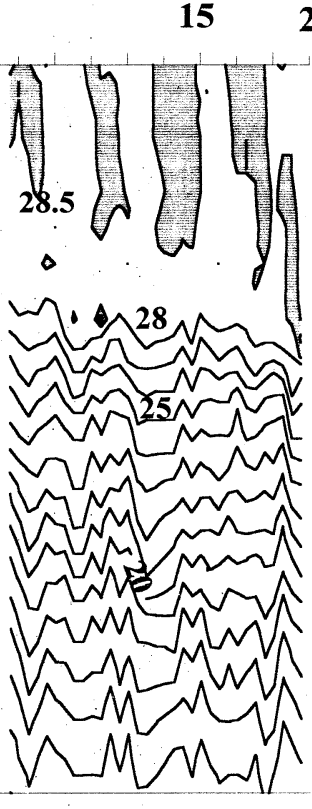

25

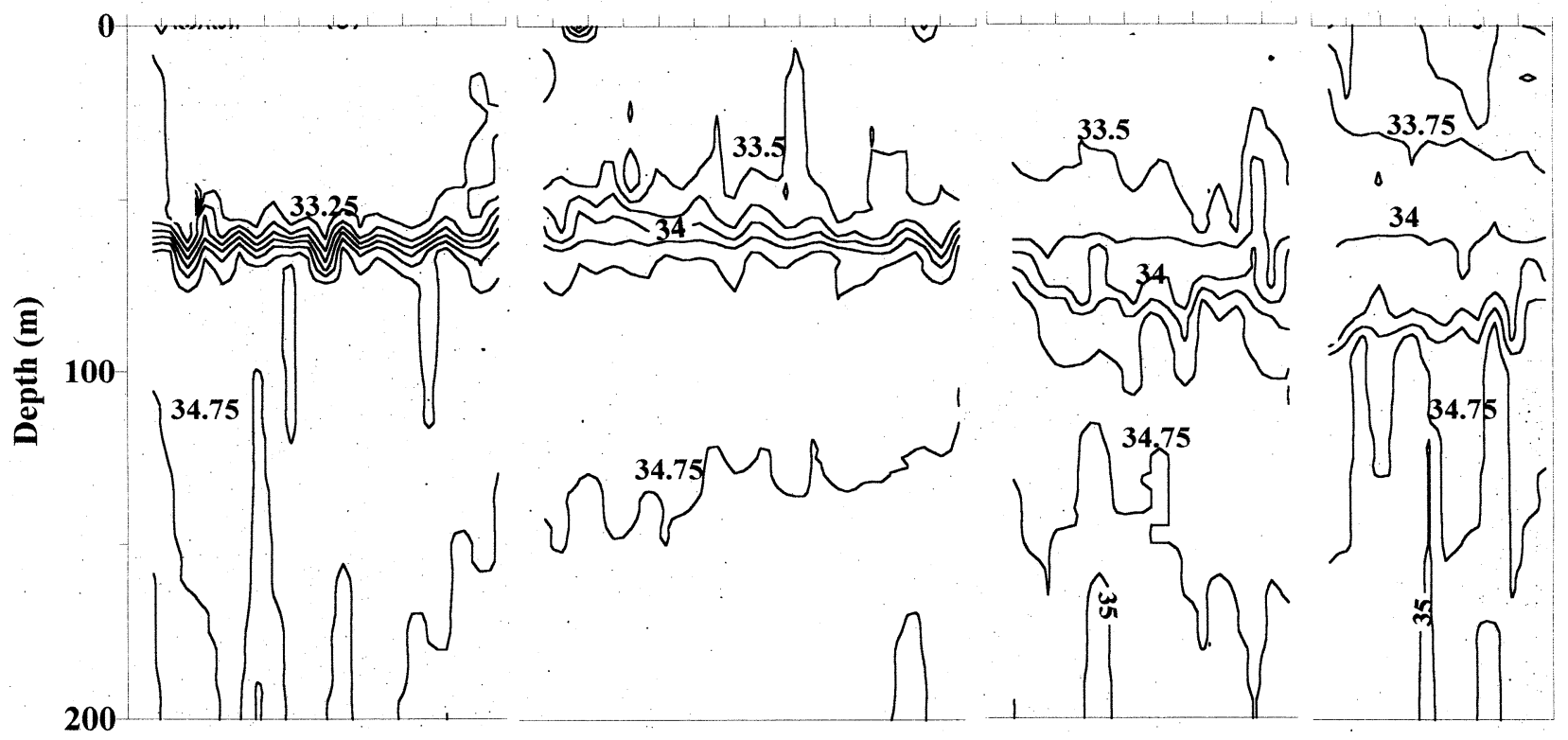

FIG. 15. Same as in Fig. 14 but for TS1.

of the temperature at TS1 is very similar to that of the Pacific. However the isothermal layer is about $60 \mathrm{~m}$ deep in the central bay compared to more than $100 \mathrm{~m}$ in the west Pacific. The mixed layer at TS1 is about $30 \mathrm{~m}$, which is similar to the Pacific, and the vertical gradient in the halocline also has similar values. Detailed analysis of the thermohaline structure to study the response of the thermohaline structure to rain/wind events and cloud-free conditions is under way.

\section{Concluding remarks}

With the successful implementation of BOBMEX, a beginning has been made in India, in special observational experiments on important facets of the coupled ocean-atmosphere system, which plays a critical role in the variability of the Indian monsoon. In this paper the experiment has been described and some initial results presented.

In the BOBMEX field phase, several active and weak spells of convection occurred over the bay. The 
observations of the variation of the atmosphere and the bay during different phases of convection have already yielded some interesting results. Highresolution radiosondes were launched for the first time in the northern bay, during BOBMEX. From these data, it has been possible to derive important information about the variation of the vertical stability of the atmosphere. CAPE and CINE values over the bay are comparable to those over the west Pacific warm pool. It has been found that the recovery time for CAPE, after a disturbance has passed, is less than 2 days. This will have important implications for the frequency of the genesis of organized convection over the bay. CINE values in the lowest 50 -mb layer decreased below $10 \mathrm{~J} \mathrm{~kg}^{-1}$ just before the onset of convection.

The thermohaline structure as well as its time evolution during the BOBMEX field phase was found to be different in the north bay than the south bay. The response of these regions to variations in convection has been documented. Studies are presently under way to ascertain the relative importance of the surface fluxes and upper ocean processes in determining the nature of the variation of SST.

Over the season as a whole, the upper-layer salinity decreased for the north bay and increased for the south bay. Over both regions, the SST and SSS generally decreased during rain events and increased in cloud-free conditions. An exception is the period of 7-13 August over the southern bay in which SST hardly changed despite large increases in OLR. The SSS increased markedly in the early stages of this event. Further analysis of the mixed layer heat and salt budgets is expected to give insight into the relative importance of surface fluxes, vertical mixing, and horizontal advection during individual events/ episodes. The variation in SST during 1999 was found to be of smaller amplitude than in 1998. Whether this can be attributed to the interannual variation in convection has to be investigated.

A large part of the BOBMEX data from observations at TS2 was distributed within the country by the end of 2000. These data will be made available to the international scientific community in 2001. Data collected at TS1 and the data on surface fluxes are being scrutinized by the investigators. Efforts are under way to distribute these data within the country this year and to the international community in 2002 .

Building on what is learned from the observations during BOBMEX and process modeling, more observational experiments will be conducted in the Indian seas to get a deeper understanding of the intraseasonal and interannual variations of the convection over these warm oceans and their implications for monsoon variability.

Acknowledgments. BOBMEX, the first observational experiment under the Indian Climate Research Program, was supported by the Department of Science and Technology, Department of Ocean Development, Defence Research and Development Organization, and Department of Space, of the government of India. The India Meteorological Department provided crucial support in the planning and field phase. The ships were provided by the National Center for Antarctic and Ocean Research and the Naval Physical and Oceanographic Laboratory, while the buoys were deployed by the National Institute of Ocean Technology. It is a pleasure to thank Drs. R. R. Kelkar, R. K. Midha, B. D. Acharya, S. M. Kulshrestha, and K. Premkumar for constant encouragement and advice; Drs. P. C. Pandey and M. Sudhakar for crucial help and support on the RV Sagar Kanya; and the director of the National Centre for MediumRange Weather Forecasts for weather analysis and advice during BOBMEX. We are grateful to the directors of the Indian Institute of Science, National Institute of Oceanography, Naval Physical and Oceanographic Laboratory, National Institute of Ocean Technology, and the director general of Meteorology, India Meteorological Department for encouraging our participation. We also thank other participants and ship crew who have helped in the collection of the data. We are grateful for the comments and suggestions on the earlier version of the manuscript by the referees, which led to substantial improvements.

\section{References}

Anderson, S. P., R. A. Weller, and R. Lukas, 1996: Surface buoyancy forcing and the mixed layer of the western equatorial Pacific warm pool: Observations and 1D model results. J. Climate, 9, 3056-3085.

Bhat, G. S., S. Ameenulla, M. Venkataramana, and K. Sengupta, 2000: Atmospheric boundary layer characteristics during the BOBMEX-Pilot experiment. Proc. Indian Acad. Sci. (Earth Planet. Sci.), 109, 229-237.

DST, 1996: Indian Climate Research Programme science plan. Department of Science and Technology, New Delhi, India, $186 \mathrm{pp}$.

Emanuel, K. A., 1994: Atmospheric Convection. Oxford University Press, 579 pp.

Fein, J. S., and J. P. Kuettner, 1980: Report on the summer of MONEX field phase. Bull. Amer. Meteor. Soc., 61, 461-474.

Gadgil, S., 2000: Monsoon-ocean coupling. Current Sci., 78, 309-323.

—, P. V. Joseph, and N. V. Joshi, 1984: Ocean-atmosphere coupling over monsoon regions. Nature, 312, 141-143.

Godfrey, J. S., and E. Lindstrom, 1989: On the heat budget of equatorial west Pacific surface mixed layer. J. Geophys. Res., 94, 8007-8017.

, R. A. Houze Jr., R. H. Johnson, R. Lukas, J. L. Redelsperger, A. Sumi, and R. Weller, 1998: Coupled OceanAtmosphere Response Experiment (COARE): An interim report. J. Geophys. Res., 103C, 14 395-14 450. 
Goel, M., and H. N. Srivastava, 1990: Monsoon Trough Boundary Layer Experiment (MONTBLEX). Bull. Amer. Meteor. Soc., 71, 1594-1600.

Gopalakrishna, V. V., V. S. N. Murty, M. S. S. Sarma, and J. S. Sastry, 1993: Thermal response of upper layers of the Bay of Bengal to forcing of a severe cyclone storm: A case study. Indian J. Mar. Sci., 22, 8-11.

Graham, N. E., and T. P. Barnett, 1987: Sea surface temperature, surface wind divergence and convection over tropical oceans. Science, 238, 657-659.

Hosom, D. S., R. A. Weller, R. E. Payne, and K. E. Prada, 1995: The IMET (Improved Meteorology) ship and buoy systems. J. Atmos. Oceanic Technol., 12, 527-540.

ICRP, 2000: BOBMEX inter-comparison report. Indian Climate Research Programme, Rept. No. ICRP/IISc/01, Centre for Atmospheric and Oceanic Sciences, Indian Institute of Science, 42 pp. [Available from G. S. Bhat, Centre for Atmospheric and Oceanic Sciences, Indian Institute of Science, Bangalore 560 012, India.]

Kingsmill, D. E., and R. H. Houze Jr., 1999: Thermodynamic characteristics of air flowing into and out of precipitating convection over the west Pacific warm pool. Quart. J. Roy. Meteor. Soc., 125, 1209-1229.

Krishnamurti, T. N., 1985: Summer monsoon experiment-A review. Mon. Wea. Rev., 113, 1590-1626.

_ , and H. N. Bhalme, 1976: Oscillations of a monsoon system. Part I. Observational aspects. J. Atmos. Sci., 33, 19371954.

— tion mode and breaks in the monsoon. Tellus, 32, 15-26.

Levitus, S., and Y. P. Boyer, 1994: Temperature. Vol. 4, World Ocean Atlas 1994, NOAA Atlas NESDIS 4, 117 pp.

Liu, W. T., K. B. Katsaros, and J. A. Businger, 1979: Bulk parameterization of air-sea exchanges of heat and water vapor including the molecular constraints at the interface. J. Atmos. Sci., 36, 1722-1735.

Lukas, R., and E. J. Lindstrom, 1991: The mixed layer of the western equatorial Pacific Ocean. J. Geophys. Res., 96 (Suppl.), 3343-3357.

Mohanty, U. C., and S. Das, 1986: On the structure of the atmosphere during suppressed and active periods of convection over the Bay of Bengal. Proc. Indian Natl. Sci. Acad., 52, 625-640.

Moncrief, M. W., and M. J. Miller, 1976: The dynamics and simulation of tropical cumulonimbus and squall lines. Quart. J. Roy. Meteor. Soc., 102, 373-394.

Murty, V. S. N., Y. V. B. Sarma, D. P. Rao, and C. S. Murty, 1992: Water characteristics, mixing and circulation in the Bay of Bengal during southwest monsoon. J. Mar. Res., 50, 207228.

,-- , and -1996 : Variability of the oceanic boundary layer characteristics in the north of the Bay of Bengal during MONTBLEX-90. Proc. Indian Acad. Sci. (Earth Planet. Sci.), 105, 41-61.

Premkumar, K., M. Ravichandran, S. R. Kalsi, D. Sengupta, and S. Gadgil, 2000: First results from a new observational system over the Indian seas. Current Sci., 78, 323-331.

Ramesh Babu, V., V. S. N. Murty, V. G. Rao, C. V. Prabhu, and V. Tilvi, 2000: Thermohaline structure and circulation in the upper layers of the southern Bay of Bengal during BOBMEX-
Pilot (October-November 1998). Proc. Indian Acad. Sci. (Earth Planet. Sci.), 109, 255-265.

Rao, R. R., 1987: Further analysis on the thermal response of the upper Bay of Bengal to the forcing of pre-monsoon cyclonic storm and summer monsoonal onset during MONEX-79. Mausam, 38, 147-156.

— - S. V. S. Somanathan, S. S. V. S. Ramakrishna, and R. Ramanadhan, 1987: A case study on the genesis of a monsoon depression in the northern Bay of Bengal during MONSOON77 experiments. Mausam, 38, 387-394.

—, R. L. Molinari, and J. F. Festa, 1989: Evolution of the climatological near-surface thermal structure of the tropical Indian Ocean. I. Description of mean monthly mixed layer depth, and sea surface temperature, surface current, and surface meteorological fields. J. Geophys. Res., 94, 10 80110815.

_ _ B. Mathew, and P. V. Hareeshkumar, 1993: A summary of results on thermohaline variability in the upper layers of the east central Arabian Sea and Bay of Bengal during summer monsoon experiments. Deep-Sea Res., 40, 1647-1672.

Rao, Y. P., 1976: Southwest monsoon. Synoptic Meteorology, Meteorological Monogr., India Meteorological Department, No. 1, 367 pp.

Sanil Kumar, K. V., N. Mohan Kumar, M. X. Joseph, and R. R. Rao, 1994: Genesis of meteorological disturbances and thermohaline variability of the upper layers in the north of Bay of Bengal during Monsoon Trough Boundary Layer Experiment (MONTBLEX-90). Deep-Sea Res., 41, 1569-1581.

Sarma, Y. V. B., P. Seetaramayya, V. S. N. Murty, and D. P. Rao, 1997: Influence of the monsoon trough on air-sea interaction in the north Bay of Bengal during the southwest monsoon of 1990. Bound.-Layer Meteor., 82, 517-526.

Sengupta, D., and M. Ravichandran, 2001: Oscillations of Bay of Bengal sea surface temperature during the 1998 summer monsoon. Geophys. Res. Lett., 28, 2033-2036.

Shetye, S. R., and A. D. Gouveia, 1998: Coastal circulation in the North Indian Ocean. Regional Studies and Syntheses, Vol. 11, The Sea: The Global Coastal Ocean, R. A. Robinson and R. H. Brink, Eds., John Wiley.

,-- D. Shankar, S. S. C. Shenoi, P. N. Vinayachandran, D. Sundar, G. S. Michael, and G. Nampoothiri, 1996: Hydrography and circulation in the western Bay of Bengal during the northeast monsoon. J. Geophys. Res., 101 (C6), $14011-14025$.

Shinoda, T., H. H. Hendon, and J. D. Glick, 1998: Intraseasonal sea surface temperature variability in the tropical Pacific and Indian Oceans. J. Climate, 11, 1685-1702.

Sikka, D. R., 1977: Some aspects of the life history, structure and movement of monsoon depressions. Pure Appl. Geophys., 115, 1501-1529.

—_ and S. Gadgil, 1980: On the maximum cloud zone and the ITCZ over India longitude during the southwest monsoon. Mon. Wea. Rev., 108, 179-195.

_ , and P. Sanjeeva Rao, 2000: Bay of Bengal Monsoon Experiment (BOBMEX) - A component of the Indian Climate Research Programme (ICRP). Proc. Indian Acad. Sci. (Earth Planet. Sci.), 109, 207-209.

Sprintall, J., and H. Tomczak, 1992: Evidence of the barrier layer in the surface layer of the tropics. J. Geophys. Res., 97 (C5), 7305-7316. 
Varkey, M. J., V. S. N. Murty, and A. Suryanarayana, 1996: Physical oceanography of the Bay of Bengal and Andaman sea. Oceanography and Marine Biology: An Annual Review, A. D. Ansell et al., Eds., Vol. 34, UCL Press, 1-70.

Vinayachandran, P. N., and S. R. Shetye, 1991: The warm pool in the Indian Ocean. Proc. Indian Acad. Sci. (Earth Planet Sci.), 100, 165-175.

Webster, P. J., and R. Lukas, 1992: TOGA COARE: The Coupled Ocean-Atmosphere Response Experiment. Bull. Amer. Meteor. Soc., 73, 1377-1416.
Weller, R. A., and S. P. Anderson, 1996: Surface meteorology and air-sea fluxes in the western equatorial Pacific warm pool during the Coupled Ocean-Atmosphere Response Experiment. J. Climate, 9, 1959-1990.

Williams, E. R., and N. Renno, 1993: An analysis of the conditional instability of the tropical atmosphere. Mon. Wea. Rev., 121, 21-35.

Yasunari, T., 1981: Structure of an Indian summer monsoon system with around 40-day period. J. Meteor. Soc. Japan, 59, 336-354.

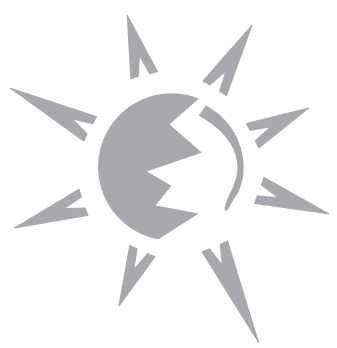

